\title{
Bayesian Network Modelling for the Wind Energy Industry: An Overview
}

\author{
Tosin Adedipe ${ }^{1}$, Mahmood Shafiee ${ }^{1,2 *}$, Enrico Zio ${ }^{3,4}$ \\ ${ }^{1}$ Department of Energy and Power, Cranfield University, Bedfordshire MK43 OAL, UK \\ ${ }^{2}$ School of Engineering and Digital Arts, University of Kent, Canterbury CT2 7NT, UK \\ ${ }^{3}$ MINES ParisTech, PSL Research University, CRC, Sophia Antipolis, France \\ ${ }^{4}$ Department of Energy, Politecnico di Milano, Via la Masa 34, Milano 20156, Italy \\ *Corresponding author.Email: m.shafiee@kent.ac.uk
}

\begin{abstract}
Wind energy farms are moving into deeper and more remote waters to benefit from availability of more space for the installation of wind turbines as well as higher wind speed for the production of electricity. Wind farm asset managers must ensure availability of adequate power supply as well as reliability of wind turbines throughout their lifetime. The operating conditions in deep water environments often change very rapidly and, therefore the decision metrics used in different phases of a wind energy project's lifecycle will have to be updated on a very frequent basis, to guarantee higher wind energy system reliability levels. For this reason, there is a crucial need for the wind energy industry to develop advanced computational tools/techniques that are capable of modelling the possible scenarios in (near) real-time and provide a prompt response to any changes in operational/environmental conditions. Bayesian network (BN) is a popular machine learning (ML) method used for system modelling and decision-making under uncertainty. This paper provides a systematic review and evaluation of existing research on the use of BN models in the wind energy sector. To conduct this literature review, all relevant databases from inception to date were searched, and a total of 70 sources (including journal publications, conference proceedings, $\mathrm{PhD}$ dissertations, industry reports, best practice documents and software user guides) which met the inclusion criteria were identified, excluding references used in other sections of the text for discussion. Our review findings reveal that the applications of BNs in the wind energy industry are quite diverse, ranging from wind power and weather forecasting to risk management, fault diagnosis and prognosis, structural analysis, reliability assessment, and maintenance planning and updating. Furthermore, a number of case studies are presented to illustrate the applicability of BNs in practice. Although the paper details information applicable to the wind energy industry, knowledge can be transferred to many other sectors.
\end{abstract}

Keywords: Wind energy; Bayesian network (BN); Operation and maintenance (O\&M); Reliability; Machine Learning (ML); Fault diagnosis and prognosis; Forecasting; Risk assessment. 


\section{Introduction}

Wind energy is one of the fastest growing and most cost-effective means of power generation worldwide. A large number of wind energy farms are currently being built or are planned to be built either on land (onshore) or at sea (offshore) - in different countries throughout the world. As reported by the Global Wind Energy Council (GWEC) in 2019, the global onshore wind capacity is 568 GW, with China contributing the highest at $36 \%$ (206 GW) followed by the USA and Germany contributing $17 \%(96 \mathrm{GW})$ and $9 \%(53 \mathrm{GW})$, respectively. In the offshore wind industry, the United Kingdom has the highest installed offshore capacity of $7.9 \mathrm{GW}$ followed by Germany and China contributing 6.38 GW and 4.59 GW, respectively (Global Wind Energy Council, 2019). The total installed capacity of onshore and offshore wind power in Europe has increased from $66 \mathrm{GW}$, as of the end of 2008, to more than $189 \mathrm{GW}$, as of the end of 2018 (see Figure 1). Among the European countries, Germany ranked first in terms of new installations in 2018 (with $29 \%$ of the total installed capacity), followed by the United Kingdom (with 16\%), France (with 13\%) and Sweden (with 6\%) (WindEurope, 2019). The total wind power capacity in Europe is estimated to reach $342 \mathrm{GW}$ and $840 \mathrm{GW}$ by 2030 and 2050 , respectively.

\section{**Figure 1**}

Figure 1. Total installed capacity of onshore and offshore wind power in Europe between 2008 and 2018.

In recent years, there has been a significant increase in the number of wind energy projects deployed in deep water and remote offshore locations (Presencia and Shafiee, 2018). These locations have more space available for the installation of large-scale wind turbines as well as more consistent wind resources for the production of electricity. Nevertheless, deepwater wind energy farms involve a lot more complexities than their onshore or shallow water counterparts. The operating conditions in deepwater environments are highly dynamic and often change very rapidly over time. Any variation in operational and environmental conditions may alter the behaviour of offshore wind turbines and their support structures and also impact the accessibility of operation and maintenance (O\&M) personnel to offshore sites. Therefore, the decision metrics used in different phases of a wind energy project's lifecycle will have to be updated on a very frequent basis.

According to the European Technology and Innovation Platform on Wind Energy (2018), O\&M is a key priority for improvement in the European wind energy sector, aiming to reduce the levelised cost of energy (LCOE). Wind farm O\&M is attracting more and more attention from industry and policy-making organizations due to its huge potential in increasing safety, efficiency, and power production. In general, there are two strategies adopted for O\&M of wind energy farms: corrective and preventive. The corrective maintenance $(\mathrm{CM})$ is a type of maintenance carried out after a failure has occurred. This strategy may lead to large production losses due to potentially long system downtime when a failure occurs. The preventive maintenance (PM) strategy, on the other hand, refers to scheduled maintenance (SM) and condition-based maintenance (CBM). The former requires scheduling of maintenance activities at predetermined time intervals, as estimated based on system's reliability, environmental conditions and other factors. The latter uses equipment condition - as assessed based on inspection reports, interpreted Supervisory Control and Data Acquisition (SCADA) data, or information gathered by sensors embedded in different parts of the wind turbines - to identify maintenance requirements. The sensor readings are recorded, inspection information is analysed, and a maintenance decision is made to address degradation before it causes a failure within the system (Shafiee, 2015).

The reliability analysis and O\&M planning of wind energy farms, in particular in deep water locations, is a complicated task as it is a function of several contributing factors such as meteorological conditions (e.g. wind speed, wave height, visibility, and sea state), failure rate of wind turbine 
components, distance to shore and water depth, availability of resources required to execute maintenance tasks (e.g. transport vessels, service crew, spare parts and special tools), etc. In order to optimise availability of wind energy farms at the lowest operating cost, an efficient planning and reporting system is crucial. Correspondingly, several quantitative and qualitative decision-making methods for reliability analysis and O\&M planning of wind energy farms have been developed in recent years. The most common methods include: Failure Mode and Effects Analysis (FMEA), Fault Tree Analysis (FTA), Event Tree Analysis (ETA), Markov Chain Analysis (MCA), Monte-Carlo Simulation (MCS), Petri Net (PN) and Fuzzy Logic (FL) (for more see Shafiee and Sørensen, 2019).

Advanced methods for the prediction of reliability and remaining useful life (RUL) of various wind farm assets (including turbines, foundations and transition pieces, export and inter-array cables, offshore substations, etc.) can contribute to the strategic O\&M planning and efficient resource allocation in wind energy farms. Thus far, reliability assessment and RUL modelling have been performed using accelerated life testing data and failure mode analysis. However, with the development of advanced sensor technologies and condition monitoring systems in the wind energy industry, a great volume of information about the external loading to the wind turbine structures as well as conditions of the surrounding environment (such as temperature, humidity, wind speed, etc.) becomes available in continuous time (Shafiee and Finkelstein, 2015). Therefore, it is necessary to develop advanced computational tools/techniques that are capable of incorporating (near) real-time data obtained from inspection results, condition-monitoring sensors or SCADA systems in order to optimise energy output and improve O\&M planning of wind energy farms. In this context, the use of Machine Learning (ML) algorithms in various applications has grown enormously in the past few years.

ML methods are capable to learn from training datasets, capture complex interactions that are difficult to model through analytical methods, and predict possible outcomes based on new observations. Of all the ML tools and techniques, the Bayesian Network (BN) seems to be the most promising framework for updating the information in (near) real-time. This is useful in situations where there is limited information about a complex system and the network has to be updated when additional information becomes available. BNs have been utilised in several industries, particularly because of their ability to treat uncertainties found in many applications. Wind energy farms, as complex systems that function under a high degree of uncertainty, can benefit from BN models by mitigating uncertainties inherent in the system's operational conditions or the surrounding environment. It is proposed that the use of Bayesian models in assessment of reliability as well as scheduling of wind farm O\&M activities can bring benefits in terms of reduction of maintenance costs and increase of power production.

The aim of this paper is to review the state-of-the-art of BN models and identify their applications in the onshore and offshore wind energy sectors, especially as they relate to the reliability of wind energy systems. Relevant databases have been searched using appropriate keywords and the studies investigating the use of BNs in the wind energy industry have been identified. These studies range from journal articles and conference papers to university dissertations, industry reports, best practice documents and software user guides. Our review findings show that the applications of BN modelling in the wind energy industry are quite diverse. The application areas include: system design, wind speed forecasting, power output modelling, data analytics, risk management, degradation modelling, fault diagnosis, cost optimisation, system reliability evaluation, as well as O\&M planning and updating. Further supporting evidence will be provided via a number of case studies found in the literature.

The organisation of this paper is as follows. Section 2 presents an overview of BNs and describes different tools that can be used for Bayesian model development and analysis. In Section 3, we discuss the review methodology adopted in this study to identify the most and least researched areas to date. Section 4 describes the case studies reported in the literature. Section 5 discusses the BN models and their application areas in the wind energy sector and, finally, Section 6 concludes the review with a discussion of major findings and additional suggestions of future research. 


\section{Overview of $\mathbf{B N}$}

\subsection{Fundamentals of $B N$}

Bayesian networks (BNs) are directed acyclic graphs (DAGs), which encode relationships among random variables represented by nodes and links (Jensen and Nielsen, 2007; Baraldi et al., 2015). The mathematical background of a BN relies on Bayes' theorem. This theorem supports the fact that the belief regarding the outcome of a system has to change when new evidence (to make probabilistic inference based on available information and quantify uncertainty when information) becomes available. Thus, BNs are also known as Belief networks (Pearl, 1988). BNs are used to solve decisionmaking problems based on recorded or prior knowledge about the system dynamics and their resultant effects. Bayes' theorem can be expressed in terms of prior probability, likelihood function and a normalisation constant to produce the posterior probability. With reference to the probability of occurrence of events, this can be expressed mathematically as:

$$
P(A \mid B)=\frac{P(B \mid A) \cdot P(A)}{P(B)},
$$

where $P(A \mid B)$ is the posterior probability (it is the conditional probability of event $A$ given the observation of evidence $B), P(A)$ is the prior probability distribution of event $A$, and $P(B \mid A)$ is the likelihood function of observing evidence $B$ when event $A$ has occurred.

A simplified $\mathrm{BN}$ model for events $A$ and $B$ is presented in Figure 2. The prior probability distributions are dependent on inputs from experts or data from inspection reports, SCADA or condition-monitoring systems, that represent stochastic or uncertain variables. Hence, the accuracy of the network depends on the quality of the input data and for the updating terms, on the quality of the newly acquired data. BNs also offer a graphical way to represent a problem space in which conditional relationships exist between two or more parameters of a system. This is also useful for making informed inference based on the output information (i.e. posterior probability distribution). For further reading, the readers can refer to the literature (Compare et al., 2017; Li et al., 2017; Fan et al., 2019).

\section{$* *$ Figure 2**}

Figure 2. A simplified BN model for events $A$ and $B$.

When developing a BN structure, some important steps should be followed. These steps include: identifying the key variables and classifying the variables, obtaining prior data, and establishing links between different nodes to construct the model. The steps of BN development can be facilitated using some well-established software development techniques. These techniques include systematic requirements engineering, ontologies, design patterns, refactoring, object-oriented and componentbased techniques (Baclawski, 2004). Different BN structures can be developed that are explained below.

\subsubsection{BN structure and learning}

In principle, a $\mathrm{BN}$ is made up of nodes and arrows which represent the system states/events and their relationships with one another, but not necessarily causality. The quantitative part of a BN is made up of conditional probability tables (CPTs) which express the quantitative relationships between the events. These CPTs represent the dependence structure within a system. The nodes in a BN represent random variables, which can be either discrete or continuous but mutually exclusive in nature. A node may take the form of a parent node (referred to as a root if it has no preceding nodes) or a child node (if it is the last node in the chain of events it will be referred to as a leaf node). The arrows, on the other hand, depict the direction of relationships within the system, where the child node is conditionally 
dependent on the parent node with the CPT showing the conditional relationship between a child node and a parent node (Cai et al., 2016). The nodes are connected via links to form different structures, including serial, converging and diverging. Fundamentally, Bayesian reasoning is used to revise beliefs based on updated evidence; thus, when a variable/node receives an evidence, it is said to be instantiated. There are two stages involved in the BN learning process (learning the manner in which BN distributions can be obtained from complete or incomplete datasets): learning the network structure and learning the parameters of the distributions. Further details about BN structures can be found in Ibe, 2011; Boudali and Dugan (2005a) and Jensen and Nielsen (2007).

\subsubsection{Dynamic $B N$ s and influence diagrams}

A dynamic Bayesian network (DBN) is a type of graphical model applicable to time-varying probabilistic inference and causal analysis under system uncertainty. The DBN was developed to compensate for the limitations of the static networks. A time stamp is used to model a time domain (either finite-horizon or infinite-horizon) at any given time point $t$; this is referred to as a time slice (Jensen and Nielsen, 2007). The two processing alternatives used to model continuous variables include discretisation and direct use of continuous variables. Also, BNs can be amended to form influence diagrams by including utility and decision nodes. A node representing a random variable in an influence diagram is called a chance node. The influence diagram also contains decision nodes, which have direct influence on other chance nodes. These decisions represented by the nodes can have cost implications, which can be represented by utility nodes. For further reading, the readers are referred to Yang and Frangopol (2018).

\subsection{Bayesian inference}

Bayesian inference is the use of BNs to compute the posterior distribution within a problem space when new observations or data are available. Owing to the flexibility of Bayesian modelling, a BN can be used to study system behaviour whilst incorporating new information when it becomes available. Therefore, the network will be updated whenever any changes are made within the system. The new information may be provided from different sources, including regular inspections or continuous monitoring of a parameter in machinery (vibration, temperature, etc.). For instance, when a wind turbine is inspected, new measurements from the inspection are inputted into the network and the posterior distribution will be updated based on the new information. In a problem space where updates are made on only one variable, the influence of other uncertain variables also will change within the network. This will cause a corresponding change in CPTs which quantify the interactive relationships between nodes/variables. In order to model continuous variables, which are inherent in dynamic processes, approximation methods/techniques will be useful. It is also quite challenging to input feedback loops to a $\mathrm{BN}$ as they are fundamentally acyclic in nature. In addition, Bayesian inference can become restrictive when the number of nodes is very large, which can result in a lower level of accuracy in the model. The need to accommodate larger system interdependencies has, therefore, led to algorithmic development in the form of approximations.

When computing the posterior distribution in Bayesian updating, inference algorithms are needed. These algorithms can be of two types: exact or approximate. The exact inference algorithms (such as junction tree algorithm, variable elimination algorithm, arc reversal method, etc.) are used for static BNs with discrete variables; whereas the approximate inference algorithms (such as loopy belief propagation algorithm, etc.) are particularly used for dynamic processes. The approximate inference algorithms are in general divided into two major categories: time-slice methods and event-based methods (Li and Mahadevan, 2018). The time-slice methods include temporal BN, DBN, network of dates, and modifiable temporal $\mathrm{BN}$; whereas, the event-based methods include Temporal Nodes BN (TNBN) and the Net of Irreversible Events in Discrete Time (NEIDT) (Borunda et al., 2016; Boudali 
and Dugan, 2005b). Different inference approximation techniques have been proposed in literature. These include discretisation, mixtures of truncated exponents, variational approximations, Bayesian search algorithms (BSA), etc. One of the advantages of BN is that it represents systems' behaviour and their interactions including both explicit and implicit connections. By using approximation inference algorithms for continuous variable inputs, two objectives are achieved: the integrity of the BN is maintained, and the model remains capable of making inferences when it is updated with new information. Nevertheless, there still remains gaps in the approximate inference methods applicable to BNs. For further reading on some of these gaps, the readers are referred to Friis-Hansen (2000); Langseth et al. (2009) and Luque and Straub (2016).

\subsection{BN software tools}

A number of software packages have been developed to date for BN modelling. These include: Microsoft MSBNx, Netica, Hugin, WinBUGS, BayesiaLab, OpenBayes, AgenaRisk and Bayesfusion. Some of these software tools have gained popularity in real life applications, depending on the context for which they are used and the scale to which they can be applied. The most widely used tools are briefly described in the following sub-sections.

\subsubsection{Microsoft MSBNx}

This is a component-based Windows application for creating, assessing, and analysing BNs (Horvitz et al., 2001). The tool is used to extract information from input database patterns as well as to show dependencies (conditional probabilities) between variables in a network. It can be used to incorporate inspection results and repair information to help asset managers perform fault diagnosis and analyse the costs/benefits of repair actions in a more timely and precise manner. An advantage it offers is that it can be integrated with other programmes to help with inference and decision-making when uncertain parameters or variables are involved. It uses Value of Information (VOI) analysis to estimate the benefit of obtaining improved posterior probabilities (Friis-Hansen, 2000). In the context of wind energy industry, this software tool was used in Li et al. (2015).

\subsubsection{Netica}

The Netica application is useful for developing belief networks and influence diagrams, which add decision and utility nodes to the Bayesian belief networks. The conditional probabilities in the network nodes can be inputted in different ways: either as individual conditional probabilities using equations or from data file inputs. It is used in Bayesian inference using different algorithms and can help in optimal decision-making when influence diagrams are set up (for more see https://www.norsys.com/netica.html).

\subsubsection{HUGIN}

HUGIN stands for Handling Uncertainty in General Inference Network. The tool is used to model parameters in a probabilistic network that are connected conditionally. It has different modules to develop, edit and analyse the BNs. These modules include a graphic user interface (GUI) module, an editor module and a compiler module. HUGIN develops a causal probabilistic network in such a way to support updating with new information for creating improved posterior probability distribution results (Andersen et al., 1989). In the context of wind energy industry, this software tool was used in Ciobanu et al. (2017).

\subsubsection{WinBUGS}

WinBUGS is an offshoot of the BUGS (Bayesian inference Using Gibbs Sampling) software tool (https://www.mrc-bsu.cam.ac.uk/software/bugs/the-bugs-project-winbugs/). It was developed for processing DAGs such as BNs. It is a user-friendly software that can be utilised to analyse different Bayesian models using different simulation methods or algorithms. With Gibbs sampling, when there 
is an update, each node is assigned an updated value based on the conditional dependence on the other nodes in the network. The modules can be extended by adding more components to the network and inputting new distribution functions within the system. The models can be presented by text or graphical form - if in text format, it is written in BUGS language. The modules making up the WinBUGS include graph, updater, monitors, BUGS, samples and Doodle. In the context of wind energy industry, this software tool was used in Li and Shi (2010).

\subsubsection{BayesiaLab}

BayesiaLab is a desktop application that uses a GUI to support modelling, diagnosis, evaluation, simulation and optimisation (http://www.bayesia.com/). This application is made up of optimised learning algorithms that can execute both exact and approximate inferences with a property called observational inference. It also updates conditional probabilities of variables and analyses how this update may affect the network propagations, allowing the analyst to find explanations for the observations within the network. BayesiaLab discretises all the continuous data inputted. It has the capability to capture the conditional probability of all variables even when the inputs are not defined, no matter how large they are. It has a 'clustering' feature which allows for data and parameter grouping, and this is useful for large input datasets (Conrady and Jouffe, 2013).

\subsubsection{AgenaRisk}

The AgenaRisk software is used to build $\mathrm{BN}$ models for qualitative risk assessment problems (https://www.agenarisk.com/). In order to produce the posterior probabilities, it uses algorithms such as dynamic discretisation algorithm and ranked mode method, which are both useful for modelling the continuous and ranked variables, respectively. The software can be used for 'what-if' simulations and sensitivity analysis, because new observations (from, for instance, the inspections) can be inputted into any of the nodes within the network. Even when there is insufficient data, the model can be updated with new information. It is possible that both forward and backward inferences are made for new probability distributions. The output can also show the risk impact of different variables considered in the model. A major advantage of this tool is that it eliminates the need for user-defined discretisation of the continuous variables through its dynamic discretisation feature. This improves the model accuracy for improved risk assessment outputs. It also has an interactive feature, which makes it easy to use. A major drawback to its widespread use is that individual licenses are restricted and they are only available on a large scale for multi-user access (Fenton and Neil, 2014). In the context of wind energy industry, this software tool was used in Ashrafi et al. (2015) and $\mathrm{Su}$ and $\mathrm{Fu}$ (2014).

\section{BN applications in wind energy industry}

\subsection{Review methodology}

In this study, the literature from academic and industry sources including journal articles, conference proceedings, $\mathrm{PhD}$ dissertations, industry reports, best practice documents and software user guides were collated for review. Different databases such as Scopus, Web of Science, IEEE Xplore Digital Library and Google scholar were searched to identify relevant studies published on the subject. The search was based on two keywords of "Bayesian network" and "wind energy" and some inclusion and exclusion criteria were defined to streamline the search content to relevant literature for the review. After reviewing the titles, abstracts and the full texts, 70 documents were eventually considered for analysis. Our analysis indicates that, in recent years, there has been a significant increase in the number of studies applying BNs in the wind energy industry. Figure 3 shows the number of studies published every year between the years 2000 and 2019. 


\section{**Figure 3**}

Figure 3. Number of publications about BNs in the wind energy industry.

Among the academic journals, the "Renewable Energy" and "Reliability Engineering \& System Safety" journals contained the largest number of articles; whereas among the conference proceedings, the "International Conference on Ocean, Offshore and Arctic Engineering" was the most represented conference.

\subsection{Applications}

BNs have been applied in different areas of the wind energy industry. These areas include: wind speed forecasting, wind power generation forecasting, risk assessment, fault diagnostic and prognostic, system reliability studies, structural analysis, O\&M planning, etc. These application areas can come under the umbrella of improved wind energy systems reliability. A brief description of these application areas is provided below.

\subsubsection{Wind speed forecasting}

Wind speed forecasting is very important to the operation of wind energy farms as it provides information that can help wind farm managers make better decisions about energy production as well as resource planning for maintenance purposes. In order to characterise stochastic variables such as wind speed, different techniques such as Bayesian model selection and Bayesian model averaging (BMA) can be used. These techniques have been used in criteria selection based on input data as well as model selection by taking into account uncertainties. BMA has the capability to predict the maximum attainable wind speed using sparse training data to generate posterior probability distributions. Numerical forecasts, and not raw wind speeds, have been used for generating the prior probability distributions (Sloughter, 2010). The posterior distribution obtained with BMA has an advantage in that it can incorporate parameter uncertainty and model uncertainty from different sets of distributions. This allows BMA to be used for creating models that can show the long-term wind speeds, while maintaining its reliability. Li and Shi (2010) applied the Markov chain Monte-Carlo (MCMC) method as a sampling method for generating wind speed distributions that may be used for wind speed forecasting. The BMA method was used to obtain the weighted average of different models for more reliable probabilistic wind speed forecasting distributions. Using the BMA method, the study demonstrated that a model generating the largest relative posterior probability would be the most ideal model to adopt for wind power forecasting.

The hybrid Bayesian-Kalman filtering and sparse Bayesian learning have also been researched for wind speed modelling. In a study by Wang et al. (2019b), a Sparse Bayesian-based robust functional regression model was proposed to forecast future wind speed for power generation estimation in wind energy farms. The input parameters were optimised using Bayesian inference algorithms for multi-steps ahead wind power and to create a template forecast for a wind turbine site in relation to other sites. The Bayesian learning and variational inference were found to be useful for reduction of 'noise' implication variables in wind forecast outputs and parameter optimisation in wind turbines, respectively. In Du (2019), an ensemble wind forecast was performed by combining three ML algorithms using BMA. This was aimed at improving the grid reliability by improving the forecasting accuracy. Some comparative studies between Bayesian and other methods for wind speed forecasting have been performed in literature. Kumar and Sahay (2018) showed that the BN regularisation algorithm is the best method for forecasting wind speed. The common theme in the wind forecasting applications are in the application for optimisation purposes and for averaging different distribution models. Other research papers on this subject area are Galanis et al. (2017); Pobočíková et al. (2017); and Han et al. (2018). 


\subsubsection{Wind power generation forecasting}

Although stochastic in nature, wind power generation forecasting is essential to estimating the reliability of the wind energy resource for the electric grid supply as well as making the electricity price competitive and maximise the revenue from wind energy projects. The power output from a wind farm can be estimated for both the short and long terms. Carta et al. (2011) used BN classifiers for wind speed and energy output estimation in long-term. Neural Network (NN) with Bayesian learning, DBN, advanced Bayesian methods and Bayesian-based regression models have also been applied to wind power generation forecasting. Some studies in this regard include Blonbou (2011); and Wang et al. (2017).

Some Bayesian methods such as Sparse Bayesian Learning can be used in conjunction with numerical methods to improve accuracy and evaluation capacity of wind power generation forecasting (Pan et al., 2015). Park and Law (2016) developed a Bayesian Ascent algorithm composing of two iterative stages: learning stage and optimisation stage. The authors tested their method on a case study to show its capability for improving the targeted wind farm power output, controlled in real-time. In another study, Xie et al. (2019) used BNs to forecast the short-term wind power generation by taking into account the uncertainty in stochastic behaviour of wind and also in the model for operational decision-making applications. A review on the applications of BN models in wind energy conversion systems was conducted by Li and Shi (2012). In Otero-Casal et al. (2019), the authors used a hybrid filter (Kalman-Bayesian) for improved wind forecasting, useful for reliable wind production forecasts. Other papers on this subject area include: Ciobanu et al. (2017); Yang et al. (2017); Afshari-Igder et al. (2018); and Wang et al. (2019a).

\subsubsection{Risk assessment}

The purpose of risk assessment is to systematically identify all hazards which can potentially lead to major incidents, assess the risks which may arise from those hazards, and decide on suitable measures to eliminate or reduce the risks. Several researchers have conducted risk assessment studies using either a single tool or a combination of two or more tools in order to combine the advantages within different tools and make up for areas in which one of them may fall short. For example, Hazard Identification (HAZID), Failure Mode, Effects and Criticality Analysis (FMECA) and BN have been combined for risk assessment studies, as reported in Kougioumtzoglou and Lazakis (2015).

In order to carry out a well-detailed risk assessment and an effective risk management strategy, wind energy managers employ advanced tools and techniques for decision-making regarding system safety. BNs have been adopted in recent years to assess the risks and make strategic O\&M decisions in the wind energy industry. Risk assessment and management frameworks can be developed using BNs. A BN model has the capability to take into account complex combinations of wind turbines' structural, electrical, mechanical, natural, political and social environmental factors, and also to show how the parameters (representing these factors) relate with one another when making sound risk-based decisions. BNs can also provide information on the effect of changes in one of the factors when there is an update in another factor, e.g. the changes in conditional reliability when there is a change in safety factors. (Ashrafi et al., 2015; Dai et al., 2013). An observed limit to BNs' ability to combine as many complex factors as possible lies in the presentation/graphic user interface (GUI), which has had very limited improvement thus far, thus it can look very cluttered and take away from the graphical property advantage. Safety assessment need to be made without the difficulties related to the GUIs in order to ensure improved wind turbine safety.

In Hybrid Bayesian Network (HBN) models, the variables associated with both static and dynamic systems can be considered. The AgenaRisk tool is useful for creating a HBN model, which provides posterior probability information about the system reliability based on system factors like time to failure 
of different components within a wind turbine system. Different factors affecting the reliability of the wind turbine can be incorporated in a HBN model and the risks associated with different elements can be quantified (Ashrafi et al., 2015).

\subsubsection{Fault diagnosis and prognosis}

In order to ensure wind energy system reliability, faults must be adequately monitored. The faults found in wind turbines can be caused by inherent material defects in components, cyclic loading or cracks. Some wind turbine components such as generator and drivetrain components are more failure-prone than others and it is crucial to adequately diagnose faults in these components for optimal maintenance planning. When a fault occurs, it can be detected either by inspection techniques such as non-destructive testing (NDT) or using advanced analytics on SCADA-based condition-monitoring data. Critical components whose failure can lead to significant downtime on a wind farm, especially the mechanical and electrical subsystems, are often continuously monitored.

With the growing use of condition monitoring and predictive maintenance on wind turbines, there has been an increasing interest in the use of BNs for fault detection and diagnosis (see Asgarpour and Sørensen, 2018a). BNs are useful in detection and diagnosis of faults in different wind turbine components. One of the early studies done on the subject of fault diagnosis and prognosis of wind turbine gearboxes using BNs is Chen and Hao (2011). BNs can also be applied to train SCADA data in order to perform fault diagnosis with the aim of lowering O\&M costs. Plumley et al. (2012) conducted a fault diagnosis and prognosis study on wind turbine gearboxes by means of DBN. The authors used the lubricant condition as an input data to model the gearbox degradation. Chen et al. (2012) applied BNs for diagnosis of failures within the pitch system of a wind turbine. They utilised SCADA data to train the $\mathrm{BN}$ model for determining root-causes of service failures in the wind turbine pitch system. A future outlook in this application anticipates an even better improvement when real-time data is collected for wind system fault diagnosis and prognosis. This will in turn improve the safety assessments, especially if it will lead to less false positives or false negatives, requiring the deployment of personnel offshore, who may be exposed to additional unecessary risks.

In a study by Stutzmann et al. (2017), BNs were used to improve the detectability of fatigue cracks in an offshore wind monopile support structure using the inspection outcomes. The fatigue life after each inspection was estimated using a Bayesian updating method. In another study, Sinha and Steel (2015) proposed a BN model to incorporate qualitative information into the estimation of failure probability. They considered four major factors, namely, system faults, operational factors, human factors and external factors (environment) in the analysis. Jing et al. (2017) matched possible fault modes with the outputs of a BN model to detect anomalies in a faster and more accurate manner. The model was a two-layer Probabilistic Signed Directed Graph (PSDG), which was made up of sensor data input and a possible-fault list input. Two sets of possible fault rankings were collected from the two layers of data input until they match. The authors used stochastic techniques to convert qualitative data into quantitative data, for ease of running the model. The method, then, uses a ranking technique to select the main faults from both layers to select the most appropriate fault type. These steps are iterated for a number of times to ensure the right fault is selected. Other references in this field include: Asgarpour and Sørensen (2018b); Fernández-Cantí et al. (2015); De Bessa et al. (2016); Joshuva and Sugumaran (2018); Zhong et al. (2019); Moghaddass and Sheng (2019); and Cai et al. (2016).

\subsubsection{Reliability assessment}

BNs have garnered attention in reliability assessment studies within different industries and the wind energy industry is not an exception. Reliability improvement is closely linked with lowering O\&M costs of wind turbines and consequently, reduction of LCOE. In one of the studies reviewed, Mardfekri and Gardoni (2013) used the BN technique for reliability assessment of offshore wind support 
structures. The analysis showed that fatigue life estimation of wind turbine support structures would benefit from Bayesian updating.

BNs have found applications also as a RUL estimation tool. Accurate estimation of RUL is important for wind farm owners and operators as well as wind turbine manufacturers. RUL estimation must be updated when inspection data is collected or new information from wind turbines is provided. DBNs are useful for incorporating updates when new information is obtained from inspections. An application of such model to wind turbine blades can be found in Nielsen and Sørensen (2017). BNs can also be used as a decision-making tool for cost-benefit analysis as well as reliability analysis of repair/replacement actions on different wind turbine components. They can be used either as a standalone tool or in conjunction with other tools such as FTA (see Herp et al., 2018; Lazakis and Kougioumtzoglou, 2019; Reder and Melero, 2018). The application of Bayesian classification methods in wind turbine health state monitoring has also been studied in Song et al. (2018).

Reliability assessments are dependent on the quality of NDT techniques, which have inherent uncertainties. These techniques will not be able to detect cracks within structural members if the length of cracks is below a certain limit. Reliability assessments are also dependent on the type of system's deterioration mechanisms, environmental factors, etc. These all will pose uncertainties to the reliability assessment, making BNs the most ideal method to quantify and update decisions when there is additional information.

Condition monitoring data can be incorporated into structural reliability analysis by fatigue failure models. Rangel-Ramírez and Sørensen (2009) presented a BN model to incorporate information from the second year of operation of an offshore wind turbine support structure into fatigue life assessment. The fatigue life updates facilitated the improvement of risk-based inspection (RBI) plans for use in fatigue prone components of offshore wind turbine structures. The wind turbine components that have mostly been studied in the past include: generator, blade, gearbox and support structure. Other papers that addressed reliability assessment of wind farms include: Sørensen and Toft (2010); Wang et al. (2013); Su and Fu (2014); Li et al. (2015); Mardfekri and Gardoni (2015); Tatsis et al. (2017); Ding et al. (2018); Song et al. (2018); and Valeti and Pakzad (2019).

\subsubsection{Structural analysis}

The wind turbines should be designed with sufficient strength and stiffness to withstand the forces to which they may be subjected during operation. The typical forces on wind turbines include: wind and wave forces, forces due to current acting on the sea, tides, temperature forces, ice forces, and earthquakes. During wind turbine design, advanced tools are required to model the components' behaviour under real environmental conditions. These models are often subject to uncertainties due to inputted data, assumptions and prediction errors. BNs can therefore be used in structural analysis during the design stage as a decision-support tool to compare different design alternatives. This potential of BNs as a decision-support tool is seen in studies on damage growth modelling for structural reliability analysis, which have been carried out using Bayesian updating in order to analyse the impact of new inspection data on structural integrity (Garbatov and Soares, 2002).

Bayesian analysis methods and Bayesian spline models can be applied to compute the effects of potential extreme events on wind turbines (see Cheng et al., 2002; Lee et al., 2013). Bayesian analysis has also been applied to study the effect of uncertainty in lifetime distribution parameters on structural integrity of wind turbines in order to select the most suitable distribution model for use in extreme response analysis (Cheng et al., 2002). The design of wind turbines will benefit from the use of probabilistic methods such as BNs. The ultimate limit state (ULS) and fatigue limit state (FLS) of wind turbine components can be modelled by Bayesian updating methods. Bayesian methods have been used to update the ULS and FLS functions for wind turbine blades. Also, Bayesian statistics and maximumlikelihood (ML) methods have been applied to update the reliability of wind turbine components (such 
as blades) after obtaining design data or inspection test results (Toft and Sørensen, 2008; Toft and Sørensen, 2011). Bayesian updating has been studied and shown to have the potential to help decision makers improve RUL predictions (see Nabdi et al., 2017; Ziegler, 2018). Improvements in structural analysis will improve the safety associated with wind energy system operations.

\subsubsection{O\&M planning and updating}

O\&M planning has a significant impact on availability as well as operating expenditure (OPEX) of wind farms (Shafiee et al., 2016). O\&M planning is not only crucial for increasing the power generation of wind farms but also plays a key role in reducing the cost of electricity production. Risk-based O\&M planning using Bayesian decision theory and DBNs have been studied in the offshore wind energy industry (see Nielsen and Sørensen, 2010a; Florian and Sørensen, 2017). Sørensen (2009) proposed a framework for risk-based O\&M planning of wind farms using BNs. This framework is illustrated in Figure 4.

\section{**Figure $4 * *$}

Figure 4. A BN decision model for risk-based O\&M planning (Sørensen, 2009).

As can be seen, there are three types of decisions, namely, the initial design $\mathbf{z}$, inspection/monitoring $\mathbf{S}$, and maintenance/repair plan $d(\mathbf{S})$. This corresponds to a pre-posterior decision problem, where the state of nature at one point is affected by previous decisions. For instance, the reliability of components is influenced by the decision on initial design, $\mathbf{z}$, and the O\&M cost of wind turbines is influenced by the decision on how and when to carry out repair tasks, given by the decision rule $d(\mathbf{S})$.

Some Bayesian methods such as Bayesian Ascent algorithms have also been applied in order to maximise wind energy production from improved O\&M (Park and Law, 2016). Bayesian classifiers have been used in conjunction with multivariate higher order moments to carry out wind turbine performance analysis. Herp et al. (2016) showed possible application of Bayesian classifiers in performing reliability assessment whilst updating inspection plans to make risk-informed O\&M decisions (Pattison et al., 2016). Wind farm power optimisation can also be performed using Bayesian method and Bayesian inference functions, as proposed in Park et al. (2017) and Mahmoud and Oyedeji (2018). The O\&M planning of wind turbines can also be carried out by combining subjective techniques like expert judgment with BNs (see Uzunoğlu, 2018). Additional references on O\&M planning using BNs are: Sørensen (2009); Nielsen and Sørensen (2011a); Nielsen and Sørensen (2011); Nielsen and Sørensen (2014); Florian and Sørensen (2017); and Nielsen and Sørensen (2017).

\subsection{Comparison between BNs and other tools}

In several studies reviewed, the results obtained by BNs have been compared with those determined by other methods. In Fernandez-Canti (2013), the performance of Bayesian approaches for fault detection in wind turbines was compared to other set-membership techniques such as subpaving method. The BN method performed better in terms of runtime. In Wang et al. (2019b), the performance of conventional models for wind speed forecasting was compared with the functional regression models. The conventional models included linear regression (LR), multi-output least square support vector machine (MLSSVM) and variational Bayesian-based linear regression (VBLR), whereas the functional regression models included Bayesian robust functional regression (R-FR) and sparse Bayesian-based functional regression (S-FR). The Bayesian robust functional regression model was shown to have the best performance rating compared to the other techniques. 
In Galanis et al. (2017), the performance of Kalman-Bayesian (K-B) filtering was compared with the conventional Kalman filter and it was found out that the K-B model did not overestimate the wind data, which would lead to more reliable predictions. In Carta et al. (2011), BNs were compared with linear regression (LR) and vector regression (VR) methods. BNs were found to be more superior to the other two methods because the output from BN had the least line of best fit with the cumulative wind frequency histograms. In Wang et al. (2017), Bayesian models were compared with prediction interval forecasts and it was shown that BNs performed much better because of their ability to generate an interval forecast at any confidence level. The authors concluded that variational Bayesian methods can be used to optimise variables and generate continuous probability density functions (PDFs) for wind power forecasting. In Friis-Hansen (2000), BN was compared with FTA and ETA for risk analysis as well as the Bogdanoff model for risk-based inspection planning. It was concluded that BNs are more efficient and flexible method compared to FTA and ETA. With respect to inspection planning, BN was found to be easier for parameter estimation. Influence diagrams (IDs) were also seen to be superior to decision trees, as they do not require a supplementary tool when performing probabilistic fatigue crack growth and probabilistic risk modelling. $\mathrm{BN}$ was also compared with neural network $(\mathrm{NN})$ and linear regression models for vessel design. It was observed that BNs, being iterative in nature, reduce the solution space for design parameters. Also, compared to NNs, the BN does not need to be relearned when new queries are made.

\section{Relevant case studies}

In this section, a number of relevant case studies from the reviewed literature are identified and described in detail. Some authors demonstrated BN applications with software tools using input data from different sources. Other authors focused on generating posterior probability density distributions based on large datasets.

\section{- $\quad$ Case studies in wind speed forecasting}

Li and Shi (2010) used the BMA method for forecasting the wind speed in nine wind farm sites. They applied eight distribution functions (including Weibull, Log-Normal, etc.) to generate the prior distribution sample data. In order to generate samples for the posterior inference estimation, MCMC sampling simulations were performed. The samples were then used for each distribution model to calculate the average posterior probability distribution for all the models, the combined likelihood of the prior distribution data to fit each model, and the posterior mean and variance of the BMA posterior probability model. The BMA posterior probability distribution curve was found to have a greater standard deviation than when only one model was considered. The posterior probability of each distribution for the nine sites was also calculated. The results included curves and histograms showing the best fitted model as well as the PDF of the BMA model. The PDF when superimposed with the individual PDFs for each site showed a complete overlap with the appropriate distribution model(s). This makes the method reliable and robust for modelling the wind speed distributions.

\section{- $\quad$ Case studies in wind power forecasting}

In a study by Xie et al. (2019), the wind power output was forecasted using hourly input data from a wind farm in 2006, and then the results were compared with other models. Gibbs sampling was used to produce different data scenarios for probabilistic wind power forecasts, in order to quantify the estimation uncertainty. The authors used two step-by-step algorithms to generate the posterior probability samples for the forecasting model and also scenarios to quantify the estimation uncertainty. Posterior probability distributions were estimated using different approaches. The non-parametric Bayesian method was found to perform better than other models when there is additional prior 
distribution data. The $\mathrm{R}$ software was used to execute the algorithms and the runtime was calculated for different volumes of data. In a dataset containing 100 variables, the runtime was 6 seconds and standard deviation was 0.6 seconds, whereas a dataset with 500 variables had a runtime of 29 seconds and a standard deviation of 1.6 seconds. The Bayesian method was found to be a more accurate forecasting tool when considering wind speed fluctuations.

\section{- $\quad$ Case studies in risk assessment}

In a case study about risk assessment of wind turbines, Ashrafi et al. (2015) captured both continuous and discrete parameters using the AgenaRisk BN software and presented several factors for a more robust analysis. The environmental, organisational, human and technical factors were considered to improve the conditional probabilistic output. The continuous nodes represented the time to failure whereas the discrete nodes represented the system states. The BN technique was used to make inference regarding the system's reliability given the different contributing factors. The case study showed that the BN analysis was useful for monitoring the risk level and system's reliability and safety in continuous operation. Kougioumtzoglo (2015) performed a study where BNs were used for ranking the criticality of wind turbine components based on their probability of failure. The results generated by the HUGIN software were compared with the results obtained by the FMECA analysis and some differences were found. A reason for such differences may be because the BN model permits adding more details when performing the analysis. Based on the study outcome, the authors further proposed the application of BNs to HAZID analysis.

\section{- $\quad$ Case studies in fault diagnosis and prognosis}

In a study, Plumley et al. (2012) applied the BN method to diagnose failures in wind turbines. The method was tested with a diagnostic program within the LabVIEW software (http://www.ni.com/en$\mathrm{gb} / \mathrm{shop} /$ labview.html) to simulate different failure modes in a wind turbine gearbox. The input variables included the parameters related to lubricant condition within the system (temperature, ferrous particle count and viscosity). Three sensors were used for data collection, which underpinned a condition monitoring method for estimating the system condition given input data. The reporting was done based on a traffic light system to help maintenance decision-makers. The second case study generated a DBN to determine the degradation rate of a wind turbine gearbox system under different conditions. The GeNIe software tool (https://www.genieonline.com/program/) was used to create the DBN model. The condition monitoring data from the sensors were used to estimate the degradation state of the gearbox. The DBN probability estimates were based on updates from new data (temperature and particle count), which were fed into new time slices of the continuous model. It presented the application of probabilistic estimates based on the updates to inform PM decisions.

In another study by Stutzmann et al. (2017), fatigue crack size distribution for an offshore wind turbine monopile structure was calculated using inspection data obtained by eddy current (EC) technique. An analysis was performed to reduce the uncertainty posed by the method of inspection. The POD by EC technique was found to be higher than that by other NDT techniques. A Bayesian analysis was then performed to estimate the fatigue crack propagation based on the crack size distribution and inspection results. From the distributions generated, the fatigue life for the crack sizes between $0.03-$ $0.06 \mathrm{~mm}$ was estimated to range between 30 and 40 years. The median and the standard deviation of the fatigue life were estimated as 33 years and 47 years, respectively. The standard deviation of the fatigue life estimation was compared for two cases, including: ( $i$ ) when the defect is detected, and (ii) when the defect is not detected. The standard deviation showed a large decrease irrespective of the inspection results. The study, therefore, concluded that the inspection serves to reduce or eliminate the risks only when the length of the crack on monopile structures is sufficiently large.

- $\quad$ Case studies in reliability assessment 
Song et al. (2018) applied a Bayesian approach to assess the health state of wind turbines. The case study was based on two 1.5MW wind turbines. The 10-minutes data was obtained from SCADA system for a period of two month. The three input variables included in the model were wind speed, power output and generator speed. Two case studies were provided, including a classical case involving the use of wind speed and power output variables and another case involving all three input variables, to evaluate how reliable and robust the results from Bayesian approach are when more data is available. This was because whenever inferences are made, it will be easier to make a trade-off between accuracy and data training. The second case involved splitting the data set into five subsets. Four subsets were used to develop the model, and the fifth one was used to test the model accuracy. The models were run five times and their performances were evaluated. The collected input data was pre-processed to identify abnormal data points. Three methods were used for this purpose, namely, the bin method, the multivariate normal distribution, and the copula method. The copula method was found to be the most robust of the three. The BN model demonstrated good health state monitoring capacity; however, the authors focused on binary health state monitoring (i.e., normal and abnormal states). Since the reliability of BN method is dependent on the input data, the authors suggested Bayesian updating to minimise issues arising due to insufficient data. The study concluded that the multivariate and copula methods are best to be used for 1-hour ahead predictions.

\section{- $\quad$ Case studies in structural analysis}

In order to illustrate the use of Bayesian analysis in studying the wind turbine's rotor blade displacement, Cheng et al. (2002) presented a case study of conditional probability distribution for blade tip deflection (influenced by wind speed). Four distribution functions were used in their study to estimate the posterior probability. These included Gumbel distribution, three-parameter Weibull distribution, log-normal distribution, and generalised extreme value (GEV) distribution. It was observed that after plotting the probability of deflection using each of the distribution functions, the threeparameter Weibull distribution and GEV distribution were the best fitted models to the input deflection data. The authors argued that the accuracy of the results would improve when well-fitted conditional distributions are used to estimate the maximum deflection of wind turbine blades. The authors estimated 100-year deflection probabilities using different distribution functions and compared the results with those calculated by Bayesian analysis. The blade tip deflection was found to be larger when a deterministic method is used. This was mainly because the Bayesian approach accounted for data uncertainty and distribution model uncertainty.

\section{- $\quad$ Case studies in O\&M planning}

In a case study that compared the efficiency of CBM strategy with risk-based maintenance (RBM) strategy, Florian and Sørensen (2017) used BN updating to model the degradation of wind turbine blades subjected to fatigue cracking. Random input variables were generated for the $\mathrm{BN}$ model for a period of 25 years (the expected lifetime of a wind turbine system). The maintenance decision-making parameters included: the time to first inspection, time interval between inspections and the repair threshold. MCS was used to generate the cost estimate distribution, taking into account different factors. The simulation procedure entailed identifying the maintenance strategies based on different inputs and then estimating the probabilities of failure and the associated repair/replacement costs. The expected number of blade failures under a CBM strategy was evaluated and the crack categories with the highest potential impact were identified. The number of preventive repair required during the blades lifetime was also calculated. The total lifecycle cost was estimated using a pre-posterior Bayesian decision tree, assuming that an inspection is carried out only when the risk of failure is high. The RBM strategy, on the other hand, was studied with a risk-based model to determine the inspection plan and the optimal repair policy after each inspection. Two hundred simulations were run to determine the average annual 
cost of O\&M. The maintenance strategies, namely, CBM and RBM resulted in different number of preventive repairs for wind turbine blades. CBM showed that $96 \%$ of the wind turbine blades required a preventive repair during their expected lifetime, whereas this percentage under RBM strategy was $62 \%$. This led to a reduction in total lifecycle cost by $23 \%$.

Dinwoodie (2013) presented a case study on an offshore wind farm consisting of 60 wind turbines installed at $45 \mathrm{~m}$ water depth. The failure rate distributions for wind turbine components such as gearbox, generator, blade and bearings were calculated. Three decision points during the lifecycle were considered: ( $i$ ) early life strategy, (ii) strategy at year seven, and (iii) strategy for the remaining lifetime. In the case study, the uncertainties upon which the $\mathrm{BN}$ was built were primarily the failure rate and the electricity price. The analysis relied on both the inspection data as well as subjective expert opinions. A risk profile was also generated and the variables causing the highest risk were identified.

Table 1 presents the case studies on different wind turbine components that have used Bayesian statistical methods in the reviewed literature. As can be seen, amongst the wind turbine components, the blade has been studied the most (13 papers). This is followed by gearbox with 11 papers, pitch system and generator with 8 papers, and support structure with 7 papers.

\section{**Table $1 * *$}

Table 1. Case studies in BN for different wind turbine components (note: some components have been studied in more than one paper)

\section{Results and discussion}

Table 2 presents the classification of reviewed literature according to their application areas, including: structural analysis, reliability, wind power forecasting, wind speed forecasting, noise emission, O\&M, fault diagnosis and prognosis, and risk assessment. All the classifications are centred around a common theme: improving the reliability of offshore wind turbine structures. The main areas of reliability improvements that have been the focus of the research community can be broken down further as seen below.

\section{$* *$ Table $2 * *$}

Table 2. Areas of BN application in the wind energy industry.

As can be seen, the field of fault diagnosis and prognosis has received the most attention in the literature. This is closely followed by wind power generation forecasting, reliability analysis, O\&M planning, and structural analysis. The fields of risk assessment and acoustic noise emission estimation, with respectively two and one publications, have been researched the least. An increasing research trend is witnessed towards the use of BNs in fault diagnosis and prognosis, power forecasting capacity, O\&M and reliability. The largest number of publications has appeared in the years 2017 and 2018, where fault diagnosis and prognosis, O\&M planning, wind power forecasting and reliability analysis with respectively 10, 8, 7 and 6 publications had the highest contributions.

In what follows, the results of the literature review for some of the most addressed application areas are briefly discussed.

- $\quad$ Wind speed forecasting

Wind speed forecasting is useful for determining the potential wind energy production. However, due to the stochastic nature of wind, it is difficult to estimate accurately a wind farm's energy 
output. For this reason, it is required to design and develop short- and long-term wind speed forecasting tools. One of the ways to forecast the wind speed is by looking into data collected from some geographically similar wind energy projects. In some cases, there is no historical data available for deepwater locations; thus, it is important to use tools through which wind farm managers can update their initial decisions when some information becomes available. This makes the case for the use of probabilistic models such as BNs. BNs have the capacity to learn based on new information inputted into the model and may be used in the $\mathrm{BN}$ classifier. Bayesian classifications help to determine the most probable value amongst a set of variables such as wind speed profile at a particular location. Beyond that, BNs also allow multiple locations to be accounted for in the estimation of wind speed and direction within the model. Although BN results were seen to be superior to the use of linear regression (LR) and vector regression (VR) models, it is still inconclusive as to whether this holds true when different correlation coefficients are considered. Thus, we have found that more research is needed in the accuracy of BN models if different correlation coefficients are considered (Carta et al, 2011).

Wind speed forecasting can also be useful for predicting periods of energy shortfall, so as to have measures in place to compensate for low energy output from wind turbines and given that BNs were used as a training tool, there is huge potential for use in a wide range of hybrid applications. Generating a probability distribution of weights is valuable for probabilistic modelling; but one key reservation regarding the applicability of this model lies in the fact that the prediction is expected to operate in real-time. However, its behaviour and performance were evaluated using pre-recorded wind speed and wind power data and evaluated offline. Additional research needs to be conducted on the real- time impact of BNN prediction scheme. Also, since the power predictions can only be reliable when there are no abrupt changes, it is difficult to state how ready this technology is to be applied to real scenarios outside of the modelling environment. If this can be improved, assumptions need to be validated for accurate results in practical terms for O\&M managers (Blonbou, 2011).

BNs are useful for short-term probabilistic wind power forecasting and are also suitable for optimising model parameters when other tools are used to forecast the wind speed. The reliability of distribution systems is predicated on accurate wind forecasts. As wind speeds are random in nature, the use of a probabilistic tool like Bayesian models to predict wind speeds required for more reliable wind power distribution. Bayesian models can easily incorporate both unimodal and bimodal wind regimes if a suitable PDF is used. One key predictor of Bayesian model adoption is its improved computational efficiency, which may promote an increase in its applicability to wind energy systems. The authors made a case for applying BN methods because a wind farm can have turbines with varying cut-in and cut-out speeds. The main limitation with its application is that to maintain computational efficiency, there is a trade-off in the power curve used in the estimations. The use of deterministic power curves is the only way to make BNs more computationally efficient. This reasoning is flawed, however, the technologies using BNs have not been developed to manage the problem yet and more research needs to be conducted in this area. It was not unusual to find that the authors used Bayesian methods for optimisation. The question thus is: if optimisation is a main application for Bayesian reasoning, what ways will it be most applicable, how and why will it be justified for use? (see Bracale and De Falco, 2015; Wang et al. 2017).

\section{- $\quad$ Risk assessment}

Risk assessment is at the heart of reliability and availability of wind turbines as wind turbines can only be efficient and available if they maintain high reliability and safety levels. Risk assessment is carried out in order to estimate the likelihood of occurrence and severity of hazards that may damage the integrity of wind farms or cause harm to the life of personnel. A number of tools and techniques are 
used for risk assessment, e.g. FMECA, HAZID, etc. In order to carry out risk assessments, it is more suitable to use a HBN, which has the capability to model dynamic states within nodes. Some particular properties of BNs as they relate to risk assessment are as follows (Ashrafi et al., 2015):

- Additional information and data about the maintenance activities can be implemented in BN and expanded. This will be useful when there is a need to include other parameters that have to be analysed for risk assessments.

- BNs can be used for both the forward (top-to-bottom) and backward (bottom-up) risk assessment approaches.

- Risk analysis can be performed to quantify the system's reliability conditioned on the impacts of environmental factors, human activities, and the selected maintenance strategy. This shows how different factors will impact the others, and provides optimal strategies for resource deployment by risk analysts and O\&M planners.

- The BN tool also allows for updating the system's reliability when there is an improvement in any of the factors considered in the network.

- Depending on the parameters to be quantified, a continuous or discrete node may be used.

- BNs can be used to represent and quantify conditional probabilities with considering different situations.

The argument for using BNs with other risk analysis tools (as a hybrid method), since deterministic methods are limited in being able to incorporate human and organisational factors in the risk assessment and analysis. The study in (Ashrafi et al., 2015) shows that it was possible to use certain variables as discrete inputs (environmental, organisational and human reliability). Although these factors are subjective in nature, a closed system is needed to capture these factors within the nodes, increasing the subjective nature of the $\mathrm{BN}$ in an attempt to increase objectivity. Thus, care must be taken in application to real applications as to how many possible child nodes can be incorporated for each variable (parent node).

In the BNs, factors like the organisation factors can practically only inputted as binary inputs (best modes or worst modes), because it takes a long time for changes in these factors to take effect. This may be a limitation in the $\mathrm{BN}$ application in reality because organisational/cultural changes are gradual and not easily measurable. This may, therefore, be good in theory but there remains a reservation for its usefulness in risk assessment accuracy in practice. Since the organisational factors cannot be modelled by distributions, as they do not have physical behaviours that can be forecasted like wind speed, for example; an attempt to include the organisational factors may not provide any particular information for improved decision-making.

\section{- $\quad$ Fault diagnosis and prognosis}

Depending on the wind turbine subsystem being analysed, different failure mechanisms may be involved. Using BNs, these failure mechanisms can be represented by nodes along with their probability of occurrence, considering other nodal probability distributions. Improved fault diagnosis and prognosis will have a positive impact on wind farm maintenance since the available resources can be effectively deployed to address any concerns based on continuously updated information. Some of the advantageous properties of BNs related to fault diagnosis and prognosis include (Chen et al, 2012; Plumley et al., 2012):

- BNs can be used to effectively determine the fault position (location).

- Component/system faults can be detected once the posterior probabilities of nodes are calculated. It is helpful to model the most critical stochastic parameters that are required for performing fault diagnosis and prognosis on the wind turbine subcomponents. 
- $\mathrm{BN}$ is a flexible tool for online fault diagnosis and prognosis, for which the O\&M planners aim to embrace in large-scale wind farms in the future. This shows the potential for real-time updating capacity of the Bayesian methods.

- BNs have the potential to lower O\&M costs in the long term as they can help wind farm asset managers quantify different variables and their relationships so as to make risk-informed O\&M decisions.

- BNs can be used to develop real-time condition-monitoring systems, which can be useful for PM planning across the wind farm.

- Data regularisation can be used to train prediction models and improve their accuracy, and this can be achieved using HBNs. Also, if updates are carried out at a higher frequency, fault diagnosis and prognosis can be improved.

- The components that have been studied for fault diagnosis and prognosis in the reviewed literature include gearbox, pitch system, bearing and support structure.

\section{- Reliability assessment}

High reliability of wind turbines ensures continuous system operation for energy production to meet the growing demand and lower the LCOE. When performing reliability assessment, there might be some unknown parameters or parameters with little to no prior information involved in the analysis. Reliability assessment can benefit from the Bayesian updating approaches in cases where there are unknown parameters, uncertain assumptions or latent variables. In such situations, the estimations can be obtained using the pre-obtained data from SCADA or experimental data (Mardfekri and Gardoni, 2013). Depending on the number of parameters to be involved in the reliability assessment, the BNs may be sufficient to accurately compute the overall conditional probability. When the problem becomes too complex, the BNs can be used in combination with other models for reliability studies. BNs can also be used as a validation tool for other reliability assessment techniques. Since the main limitations in using the BNs are based on the presentation of the nodal relationships and model uncertainties, one of the key improvements required in BNs tools are related to the GUI (graphic user interface) of the modelling tool. In terms of the computational capacity, the BN is believed to have capacity for updating, which should be an addition for its use in reliability assessment (Li et al., 2015). The Bayesian reasoning can show any weak connections within the subsystem when calculating reliability at a design stage. The weak connections are identified by the BNs' backward reasoning capability (see Jin and Liu, 2017). Besides using BN as a verification tool, other tools and techniques such as FMECA can be used to verify $\mathrm{BN}$ results. The $\mathrm{BN}$ model will be updated when there is new information that can be inputted to show the most accurate state of the system, thus informing better maintenance plans. Even though BNs have the capacity to update, on the operations side, there has to be more efficient means of data collection and updating for the BN capacity to be maximised. (Lazakis and Kougioumtzoglou, 2019). The components that have been studied for reliability assessment in the reviewed literature include generator, blade and gearbox.

\section{- $\quad$ O\&M planning}

Improving the O\&M practices is vital to optimise wind farm availability and maximise wind power output. Many tools are used by wind farm asset managers to optimise O\&M strategies, but Bayesian methods have shown potential for improvement in O\&M planning. Some of the properties that make BNs attractive for use in O\&M planning include (see Nielsen and Sørensen, 2010b; Cheng et al., 2002):

- Both logical and stochastic nodes can be incorporated in BNs. This results in a more robust O\&M planning model. 
- Continuous nodes can be included in BNs when an approximate inference is used (e.g. discretisation of distribution parameters).

- Condition monitoring data and inspection outputs can be incorporated into the BN structure in order to update the O\&M decisions when needed.

- Bayesian learning approaches can be used to incorporate different parameters such as defect (crack) size in the estimation of propagation rates. This informs O\&M planners about the optimal time to repair or replace the failed parts, especially in deepwater locations where accessibility is restricted.

- Besides being able to model stochastic processes with limited information and very minimal data points, an approximation tool such as Bayesian Ascent algorithm can model complex relationships within a system, and when more information is obtained, more data points can be added for improving the estimation accuracy.

- Annual probability of failure estimates will be lower if observations are incorporated into the model. Thus, a strong case is made for when monitoring results are included in a model, as it will increase the confidence levels of failure predictions.

BN-based O\&M planning tools can be useful for more accurate RUL estimation using real-time updates of critical subsystems. This will result in reduced cost of repairs as well as improved availability of wind turbines. As BNs have the capability to process limited data and to update the results when new information becomes available, they prove to be very useful for deepwater sites where floating wind farms will be developed in the future.

A detailed analysis of the reviewed studies in terms of their model inputs, outputs, specifications, challenges of the solutions, advantages and limitations is presented in Table A in Appendix.

\section{Conclusion and future work}

Wind energy systems often operate in highly dynamic and ever-changing environments; thus, their condition may change rapidly over time. In such environments, reliability is more difficult to achieve for several reasons and thus, different areas in wind farm management must be improved or adapted for complex and dynamic conditions. It is crucial for wind farm managers to update their decisions and actions continuously, taking into account changes in operational/environmental conditions and/or newly collected data. The new data is usually provided from the inspection reports, Supervisory Control and Data Acquisition (SCADA) systems or the sensors fitted to different parts of the wind turbines.

Among all the Machine Learning (ML) tools and techniques that allow for updating, Bayesian networks (BNs) are the most promising method for real-time planning. This is because BNs can be used to quantify uncertainty when solving a decision-making problem, based on recorded or prior knowledge about the system dynamics and their resultant effects. They are useful in situations where there is limited information about a complex system and the environment, which is the case for wind energy systems, and the network can be updated when additional information becomes available.

In this paper, we conducted a systematic literature review on the use of BN models in the onshore and offshore wind energy industry. Several documents were identified and analysed for the purpose of this review. It was found that the major applications of BNs in the wind energy industry include: wind speed forecasting, wind power generation forecasting, risk assessment and management, fault diagnosis and prognosis, system reliability studies, structural analysis, and operation and maintenance (O\&M) planning. An overarching theme was observed in all those applications: the need for improved reliability. If wind speed and power forecasting is improved using an updating method like BNs, there will be more reliable grid supply data to adequately meet energy demand. Also, improving risk assessment and management will ensure improved system availability and better planning and decision- 
making. Improved fault diagnosis and prognosis, structural analysis, O\&M are central to wind system reliability. A detailed review of the publications, thus, shows that the areas of fault diagnosis and prognosis, reliability analysis, O\&M planning, wind power generation forecasting and structural analysis have been the most researched areas. One of the reasons maybe is that if fault diagnosis and prognosis can be improved by a tool with the ability of real-time updating, the reliability of wind turbines as well as O\&M practices will also be improved. This eventually will result in an increased O\&M efficiency as well as reduced LCOE in the wind energy industry.

In spite of various applications of BN modelling in the wind energy industry, future work is needed to improve the prediction performance of $\mathrm{BN}$ algorithms, particularly the newly developed cyclic Bayesian approximation models. BNs and their approximation models have the potential to help wind farm asset managers move towards 'real-time' predictive analytics. The uncertainties lying within the system performance, stochastic environmental conditions and model can be quantified and subsequently modified with field information to facilitate improved decision-making processes. Hybrid models like the Bayesian-Kalman filtering, sparse Bayesian learning, etc. were more common in different studies, in order to compensate for the current limitations of BNs. A common trend in Bayesian method applications are seen in its use because of its good optimisation and model averaging properties during wind forecasting, to improve the confidence levels of posterior probability outputs. Although BNs have the capacity to combine different complex combinations of wind turbines' structural, electrical, mechanical, natural, political and social environmental factors, the GUI development of BN tools have not improved at the same rate.

The uncertainty caused by the selection of the inspection technique can also be incorporated into BNs, which shows a usefulness of the method, especially because not all inspection method has $100 \%$ detectability in every instance. BN model demonstrated good health state monitoring capacity and because the reliability of BN method depends on the input data, Bayesian updating will help manage issues arising due to insufficient data. An advanced reliability and RUL prediction tool like BNs will be able to take advantage of the real-time data from condition monitoring improvements in the wind energy industry. The potential that Bayesian updating can have on decision-support optimisation for improved system structural analysis, RUL and reliability predictions has also been discussed; this can address issues in predictions caused by insufficient data. When data can be updated using BNs, it will be easier to estimate with higher confidence levels the reliability, risks/safety associated with the wind turbine structures and operations. Some areas that show potential for future research direction include:

- More models need to be developed using BN algorithms in order to make tools more robust, reliable and efficient for different wind energy applications;

- Damage growth models using Bayesian statistics still require improvements, especially, for small size damages in wind turbine structures;

- A future outlook in fault prognosis and diagnosis application is expected to bring application improvements when real-time data is collected for wind system fault diagnosis and prognosis.

- Bayesian inference techniques must be improved in order for models to combine corrosion effects along with fatigue deterioration in reliability studies;

- BNs can be used as a decision support tool for modelling life extension strategies in wind farms (for more see Shafiee and Animah, 2017).

- Because wind power predictions with BNs to-date are reliable when there are no abrupt changes, the technology readiness is difficult to state for application in real scenarios outside of the modelling environment. For this to be improved, assumptions for wind power predictions using BNs need to be validated for accurate results in practical terms for O\&M managers (Blonbou, 2011). 


\section{Acknowledgement}

The authors acknowledge the funding support from the EPSRC on Supergen Wind Hub in a project titled "Stochastic Methods and Tools to Support 'Real-Time' Planning of Risk-based Inspection for Offshore Wind Structures" http://supergenwind-r4.com/.

\section{References}

Afshari-Igder, M., Niknam, T., and Khooban, M.H. (2018). Probabilistic wind power forecasting using a novel hybrid intelligent method. Neural Computing and Applications, 30(2), 473-485.

Andersen, S.K., Olesen, K.G., Jensen, F.V. and Jensen, F. (1989). HUGIN - a Shell for building Bayesian belief universes for expert systems. In: Proceedings of the 11th International Joint Conference on Artificial Intelligence - Volume 2, 20-25 August, Detroit, Michigan, USA.

Asgarpour, M. and Sørensen, J.D. (2018a). Bayesian based prognostic model for predictive maintenance of offshore wind farms. International Journal of Prognostics and Health Management, 10, 9 pages. Retrieved from https://www.phmsociety.org/sites/phmsociety.org/files/phm_submission/2017/ijphm_18_010.pdf

Asgarpour, M. and Sørensen, J.D. (2018b). Bayesian based diagnostic model for condition based maintenance of offshore wind farms. Energies, 11, pp. 1-17.

Ashrafi, M., Davoudpour, H., and Khodakarami, V. (2015). Risk assessment of wind turbines: Transition from pure mechanistic paradigm to modern complexity paradigm. Renewable and Sustainable Energy Reviews, $51,347-355$.

Baclawski, K. (2004). Bayesian network development. In: Proceedings of the $4^{\text {th }}$ International Workshop on Software Methodologies, Tools and Techniques. Tokyo, Japan, pp. 18-48.

Baraldi, P., Podofillini, L., Mkrtchyan, L., Zio, E. and Dang, V. N. (2015). Comparing the treatment of uncertainty in Bayesian networks and fuzzy expert systems used for a human reliability analysis application. Reliability Engineering and System Safety, 138, 176-193.

Blonbou, R. (2011). Very short-term wind power forecasting with neural networks and adaptive Bayesian learning. Renewable Energy, 36(3), 1118-1124.

Borunda, M., Jaramillo, O.A., Reyes, A. and Ibargüengoytia, P.H. (2016). Bayesian networks in renewable energy systems: A bibliographical survey. Renewable and Sustainable Energy Reviews, 62, 32-45.

Boudali, H. and Dugan, J.B. (2005a). A discrete-time Bayesian network reliability modeling and analysis framework. Reliability Engineering and System Safety, 87(3), 337-349.

Boudali, H. and Dugan, J.B. (2005b). A new Bayesian network approach to solve dynamic fault trees. In: Proceedings of IEEE Annual Reliability and Maintainability Symposium, 24-27 January, Alexandria, USA, pp. 451-456.

Bracale, A., and De Falco, P. (2015). An advanced Bayesian method for short-term probabilistic forecasting of the generation of wind power. Energies, 8(9), 10293-10314.

Cai, B., Liu, H. and Xie, M. (2016). A real-time fault diagnosis methodology of complex systems using objectoriented Bayesian networks. Mechanical Systems and Signal Processing, 80, 31-44.

Carta, J.A., Velázquez, S. and Matías, J.M. (2011). Use of Bayesian networks classifiers for long-term mean wind turbine energy output estimation at a potential wind energy conversion site. Energy Conversion and Management, 52(2), 1137-1149.

Chen, J. and Hao, G. (2011). Research on the fault diagnosis of wind turbine gearbox based on Bayesian networks. In: Practical applications of intelligent systems, Wang, Y and Li, T. (Eds.). pp. 217-223. https://link.springer.com/content/pdf/10.1007\%2F978-3-642-25658-5.pdf

Chen, B., Tavner, P.J., Feng, Y., Song, W.W. and Qiu, Y. (2012). Bayesian networks for wind turbine fault diagnosis. In: European Wind Energy Conference, 16-19 April, Copenhagen, Denmark, 9 pages.

Cheng, P. W., van Kuik, G.A.M., van Bussel, G.J.W., and Vrouwenvelder, A.C.W.M. (2002). Bayesian analysis applied to statistical uncertainties of extreme response distributions of offshore wind turbines. Wind Engineering, 26(3), 157-169.

Ciobanu, A., Munteanu, F., Nemes, C., and Astanei, D. (2017). Data-driven Bayesian networks for reliability of supply from renewable sources. In: Proceedings of International Conference on Optimization of Electrical 
and Electronic Equipment and International Aegean Conference on Electrical Machines and Power Electronics, 25-27 May 2017, Brasov, Romania, pp. 84-89.

Compare, M., Baraldi, P., Bani, I., Zio, E. and Mc Donnell, D. (2017). Development of a Bayesian multi-state degradation model for up-to-date reliability estimations of working industrial components. Reliability Engineering and System Safety, 166, 25-40.

Conrady, S., and Jouffe, L. (2013). Introduction to Bayesian networks and BayesiaLab. https://library.bayesia.com/download/attachments/10092794/Bayesian_Networks_Intro_v16.pdf (accessed on 11.02.2019).

Dai, L., Ehlers, S., Rausand, M. and Utne, I. B. (2013). Risk of collision between service vessels and offshore wind turbines. Reliability Engineering and System Safety, 109, 18-31.

De Bessa, I.V., Palhares, R.M., D’Angelo, M.F.S.V. and Filho, J.E.C. (2016). Data-driven fault detection and isolation scheme for a wind turbine benchmark. Renewable Energy, 87, 634-645.

Ding, F., Tian, Z., Zhao, F. and Xu, H. (2018). An integrated approach for wind turbine gearbox fatigue life prediction considering instantaneously varying load conditions. Renewable Energy, 129, 260-270.

Dinwoodie, I., McMillan, D., Revie, M., Lazakis, I. and Dalgic, Y. (2013). Development of a combined operational and strategic decision support model for offshore wind. Energy Procedia, 35, 157-166.

Du, P. (2019). Ensemble machine learning based wind forecasting to combine NWP output with data from weather stations. IEEE Transactions on Sustainable Energy, 10(4), 2133-2141.

European Technology and Innovation Platform on Wind Energy. (2018). Strategic Research and Innovation Agenda. 22 pages, Available at: https:/etipwind.eu/wp-content/uploads/2018-Strategic-ResearchInnovation-Agenda.pdf. (accessed on 28.12.2019).

Fan, M., Zeng, Z., Zio, E., Kang, R. and Chen, Y. (2019). A sequential Bayesian approach for remaining useful life prediction of dependent competing failure processes. IEEE Transactions on Reliability, 68(1), 317329.

Fenton, N. and Neil, M. (2004). Combining evidence in risk analysis using Bayesian networks. Agena White Paper W0704/01, Version 01.01, 6 pages. Available at: https://www.eecs.qmul.ac.uk/ norman/papers/Combining\%20evidence $\% 20 \mathrm{in} \% 20 \mathrm{risk} \% 20$ analysis $\% 20 \mathrm{us}$ ing $\% 20 B N s . p d f$

Fernández-Cantí, R. M., Blesa, J., Tornil-Sin, S. and Puig, V. (2015). Fault detection and isolation for a wind turbine benchmark using a mixed Bayesian/Set-membership approach. Annual Reviews in Control, 40, 5969.

Fernández-Cantí, R. M., Tornil-Sin, S., Blesa, J. and Puig, V. (2013). Nonlinear set-membership identification and fault detection using a Bayesian framework: Application to the wind turbine benchmark. In: Proceedings of the IEEE Conference on Decision and Control, 10-13 December, Florence, Italy, pp. 496501.

Florian, M. and Sørensen, J.D. (2017). Risk-based planning of operation and maintenance for offshore wind farms. Energy Procedia, 137, 261-272.

Friis-Hansen, A. (2000). Bayesian networks as a decision support tool in marine applications. PhD Thesis. Technical University of Denmark (DTU), Denmark. Retrieved from http://orbit.dtu.dk/files/5445991/Andreas.pdf

Galanis, G., Papageorgiou, E., and Liakatas, A. (2017). A hybrid Bayesian Kalman filter and applications to numerical wind speed modeling. Journal of Wind Engineering and Industrial Aerodynamics, 167, 1-22.

Garbatov, Y. and Soares, C.G. (2002). Bayesian updating in the reliability assessment of maintained floating structures. Journal of Offshore Mechanics and Arctic Engineering, 124(3), 139-145.

Global Wind Energy Council (EWEC). Global Wind Report 2018. Available at: https://gwec.net/wpcontent/uploads/2019/04/GWEC-Global-Wind-Report-2018.pdf, April 2019.

Han, K., Choi, J. T. and Kim, C. (2018). Comparison of statistical post-processing methods for probabilistic wind speed forecasting. Asia-Pacific Journal of Atmospheric Sciences, 54(1), 91-101.

Herp, J., Pedersen, N.L. and Nadimi, E.S. (2016). Wind turbine performance analysis based on multivariate higher order moments and Bayesian classifiers. Control Engineering Practice, 49, 204-211.

Herp, J., Ramezani, M.H., Bach-Andersen, M., Pedersen, N.L. and Nadimi, E.S. (2018). Bayesian state prediction of wind turbine bearing failure. Renewable Energy, 116, 164-172. 
Horvitz, E., Hovel, D., Kadie, C. (2001). MSBNx: A component-centric toolkit for modeling and inference with Bayesian networks. Microsoft Research, Richmond, WA. Retrieved from: http://131.107.65.14/pubs/69867/tr-2001-67.doc

Ibe, O.C. (2011). Fundamentals of Stochastic Networks. John Wiley, Hoboken, New Jersey, USA.

Jensen, F.V. and Nielsen, T.D. (2007). Bayesian networks and decision graphs. Springer-Verlag, New York, USA.

Jin, H. and Liu, C. (2017). Reliability analysis of wind turbine gear box based on fault tree and Bayesian network. In: Proceedings of the 29th Chinese Control and Decision Conference, 28-30 May, Chongqing, China, pp. 4681-4686. https://doi.org/10.1109/CCDC.2017.7979324.

Jing, Y., Ning, L. and Shaoyuan, L. (2017). Two-layer PSDG based fault diagnosis for wind turbines. In: 36th Chinese Control Conference, 26-28 July, Dalian, China, pp. 7148-7154.

Joshuva, A. and Sugumaran, V. (2018). A machine learning approach for condition monitoring of wind turbine blade using autoregressive moving average (ARMA) features through vibration signals: a comparative study. Progress in Industrial Ecology - An International Journal, 12(1/2), 14-34.

Kougioumtzoglou, M.A. and Lazakis, I. (2015). Developing a risk analysis and decision making strategy for an offshore wind farm. In: 5th International Symposium on Ship Operations, Management and Economics, 28-29 May, Athens, Greece, 8 pages.

Kumar, S. and Sahay, K.B. (2018). Wind speed forecasting using different neural network algorithms. In: $2 n d$ International Conference on Electronics, Materials Engineering and Nano-Technology, IEMENTech 2018, 4-5 April, Kolkata, India, pp. 1-4.

Langseth, H., Nielsen, T.D., Rumí, R. and Salmerón, A. (2009). Inference in hybrid Bayesian networks. Reliability Engineering and System Safety, 94(10), 1499-1509.

Lazakis, I. and Kougioumtzoglou, M.A. (2019). Assessing offshore wind turbine reliability and availability. Journal of Engineering for the Maritime Environment, 233(1), 267-282.

Lee, G., Byon, E., Ntaimo, L. and Ding, Y. (2013). Bayesian spline method for assessing extreme loads on wind turbines. The Annals of Applied Statistics, 7(4), 2034-2061.

Li, C. and Mahadevan, S. (2018). Efficient approximate inference in Bayesian networks with continuous variables. Reliability Engineering and System Safety, 169, 269-280.

Li, G. and Shi, J. (2010). Application of Bayesian model averaging in modeling long-term wind speed distributions. Renewable Energy, 35(6), 1192-1202.

Li, G., and Shi, J. (2012). Applications of Bayesian methods in wind energy conversion systems. Renewable Energy, 43, 1-8.

Li, Y. F., Valla, S., and Zio, E. (2015). Reliability assessment of generic geared wind turbines by GTST-MLD model and Monte Carlo simulation. Renewable Energy, 83, 222-233.

Li, X., Hu, Y., Zio, E. and Kang, R. (2017). A Bayesian optimal design for accelerated degradation testing based on the Inverse Gaussian process. IEEE Access, 5, 5690-5701.

Luque, J., and Straub, D. (2016). Reliability analysis and updating of deteriorating systems with dynamic Bayesian networks. Structural Safety, 62, 34-46.

Mahmoud, M. S., and Oyedeji, M. O. (2018). Continuous-time multi-model predictive control of variable-speed variable-pitch wind turbines. International Journal of Systems Science, 49(11), 2442-2453.

Mardfekri, M., and Gardoni, P. (2013). Probabilistic demand models and fragility estimates for offshore wind turbine support structures. Engineering Structures, 52, 478-487.

Mardfekri, M., and Gardoni, P. (2015). Multi-hazard reliability assessment of offshore wind turbines. Wind Energy, 18(8), 1433-1450.

Moghaddass, R. and Sheng, S. (2019). An anomaly detection framework for dynamic systems using a Bayesian hierarchical framework. Applied Energy, 240, 561-582.

Nabdi, S., Zaghar, H., and Herrou, B. (2017). Bayesian modeling of a wind turbine system in the preliminary design phase. Journal of Engineering Science and Technology Review, 10(4), 185-190. https://doi.org/10.25103/jestr.104.22

Nielsen, J.J., and Sørensen, J.D. (2010a). Bayesian networks as a decision tool for O\&M of offshore wind turbines. In: 5th International ASRANet Conference on Integrating Structural Analysis, Risk \& Reliability, 14-16 June, Edinburgh, UK, 8 pages. 
Nielsen, J.J., and Sørensen, J.D. (2010b). Planning of O\&M for offshore wind turbines using Bayesian graphical models. In: European Safety and Reliability Conference, 5-9 September, Rhodes, Greece, 8 pages.

Nielsen, J.J., and Sørensen, J.D. (2011). On risk-based operation and maintenance of offshore wind turbine components. Reliability Engineering and System Safety, 96(1), 218-229.

Nielsen, J.S. and Sørensen, J.D. (2014). Methods for risk-based planning of O\&M of wind turbines. Energies, 7(10), 6645-6664.

Nielsen, J.S. and Sørensen, J.D. (2017). Bayesian estimation of remaining useful life for wind turbine blades. Energies, 10(5), 13 pages.

Otero-Casal, C., Patlakas, P., Prósper, M. A., Galanis, G. and Miguez-Macho, G. (2019). Development of a highresolution wind forecast system based on the WRF model and a hybrid Kalman-Bayesian filter. Energies, 12(16), 19 pages.

Pan, K., Qian, Z. and Chen, N. (2015). Probabilistic short-term wind power forecasting using sparse Bayesian learning and NWP. Mathematical Problems in Engineering, Volume 2015, Article ID 785215, 11 pages.

Park, J. and Law, K.H. (2016). Bayesian ascent: A data-driven optimization scheme for real-time control with application to wind farm power maximization. IEEE Transactions on Control Systems Technology, 24(5), $1655-1668$.

Park, J., Kwon, S.-D.K. and Law, K. (2017). A data-driven, cooperative approach for wind farm control: a wind tunnel experimentation. Energies, 10(7), 17 pages.

Pattison, D., Segovia Garcia, M., Xie, W., Quail, F., Revie, M., Whitfield, R.I. and Irvine, I. (2016). Intelligent integrated maintenance for wind power generation. Wind Energy, 19(3), 547-562.

Pearl, J. (1988). Probabilistic Reasoning in Intelligent Systems. Morgan Kaufmann Publishers Inc., San Francisco, California, USA.

Plumley, C., Wilson, G., Kenyon, A., Quail, F. and Zitrou, A. (2012). Diagnostics and prognostics utilising dynamic Bayesian networks applied to a wind turbine gearbox. In: 9th International Conference on Condition Monitoring and Machinery Failure Prevention Technologies, 12-14 June, London, UK.

Pobočíková, I., Sedliačková, Z., and Michalková, M. (2017). Application of four probability distributions for wind speed modeling. Procedia Engineering, 192, 713-718.

Presencia, C.E. and Shafiee, M. (2018). Risk analysis of maintenance ship collisions with offshore wind turbines. International Journal of Sustainable Energy, 37(6), 576-596.

Rangel-Ramírez, J.G. and Sørensen, J.D. (2009). Maintenance planning of offshore wind turbine using condition monitoring information. In: Proceedings of the ASME 28th International Conference on Ocean, Offshore and Arctic Engineering, Honolulu, Hawaii, USA, May 31-June 5, pp. 1-8.

Reder, M. and Melero, J. J. (2018). A Bayesian approach for predicting wind turbine failures based on meteorological conditions. Journal of Physics: Conference Series, 1037(6), 11 pages. https://doi.org/10.1088/1742-6596/1037/6/062003.

Shafiee, M. (2015). Maintenance logistics organization for offshore wind energy: Current progress and future perspectives. Renewable Energy, 77(1), 182-193.

Shafiee, M. and Animah, I. (2017) Life extension decision making of safety critical systems: An overview. Loss Prevention in the Process Industries, 47, 174-188.

Shafiee, M., Brennan, F. and Espinosa, I.A. (2016). A parametric whole life cost model for offshore wind farms. International Journal of Life Cycle Assessment, 21(7), pp 961-975.

Shafiee, M. and Finkelstein, M. (2015). A proactive group maintenance policy for continuously monitored deteriorating systems: Application to offshore wind turbines. Proceedings of the Institution of Mechanical Engineers, Part O: Journal of Risk and Reliability, 229(5), 373-384.

Shafiee, M. and Sørensen, J. D. (2019). Maintenance optimization and inspection planning of wind energy assets: Models, methods and strategies. Reliability Engineering and System Safety, 192, 105993.

Sinha, Y., and Steel, J. A. (2015). Failure prognostic schemes and database design of a software tool for efficient management of wind turbine maintenance. Wind Engineering, 39(4), 453-477.

Sloughter, J.M., Gneiting, T., and Raftery, A.E. (2010). Probabilistic wind speed forecasting using ensembles and Bayesian model averaging. Journal of the American Statistical Association, 105(489), 25-35.

Song, Z., Zhang, Z., Jiang, Y. and Zhu, J. (2018). Wind turbine health state monitoring based on a Bayesian datadriven approach. Renewable Energy, 125, 172-181. 
Sørensen, J.D. (2009). Framework for risk-based planning of operation and maintenance for offshore wind turbines. Wind Energy, 12(5), 493-506.

Sørensen, J.D., and Toft, H. S. (2010). Probabilistic design of wind turbines. Energies, 3(2), 241-257.

Stutzmann, J., Ziegler, L. and Muskulus, M. (2017). Fatigue crack detection for lifetime extension of monopilebased offshore wind turbines. Energy Procedia, 137, 143-151.

$\mathrm{Su}, \mathrm{C}$. and Fu, Y. (2014). Reliability assessment for wind turbines considering the influence of wind speed using Bayesian network. Eksploatacja i Niezawodność 16(1), 1-8.

Tatsis, K., Dertimanis, V., Abdallah, I., and Chatzi, E. (2017). A substructure approach for fatigue assessment on wind turbine support structures using output-only measurements. In: Procedia Engineering 199, 10441049.

Toft, H.S. and Sørensen, J.D. (2011). Reliability-based design of wind turbine blades. Structural Safety, 33(6), 333-342.

Toft, H.S., Branner, K., Berring, P. and Sørensen, J.D. (2011). Defect distribution and reliability assessment of wind turbine blades. Engineering Structures, 33(1), 171-180.

Uzunoğlu, B. (2018). Bayesian approach with subjective opinion fusions for wind turbine maintenance. Journal of Physics: Conference Series, 1037(6), 10 pages. https://doi.org/10.1088/1742-6596/1037/6/062021

Valeti, B. and Pakzad, S.N. (2019). Estimation of remaining useful life of a fatigue damaged wind turbine blade with particle filters. In: Dynamics of Civil Structures, Volume 2, S. Pakzad (Ed.), pp. 319-328, Springer.

Van Buren, K.L., Mollineaux, M.G., Hemez, F.M. and Atamturktur, S. (2013). Simulating the dynamics of wind turbine blades: part II, model validation and uncertainty quantification. Wind Energy, 16 (5), 657-669.

Wang, B., Wang, Y., and Chen, X. (2013). Research on wind turbine generator dynamic reliability test system based on feature recognition. Research Journal of Applied Sciences, Engineering and Technology, 6(16), 3065-3071.

Wang, Y., Hu, Q., Meng, D., and Zhu, P. (2017). Deterministic and probabilistic wind power forecasting using a variational Bayesian-based adaptive robust multi-kernel regression model. Applied Energy, 208, 10971112.

Wang, Y., Hu, Q., Srinivasan, D. and Wang, Z. (2019a). Wind power curve modeling and wind power forecasting with inconsistent data. IEEE Transactions on Sustainable Energy, 10(1), 16-25.

Wang, Y., Wang, H., Srinivasan, D. and Hu, Q. (2019b). Robust functional regression for wind speed forecasting based on Sparse Bayesian learning. Renewable Energy, 132, 43-60.

Weber, P. and Jouffe, L. (2006). Complex system reliability modelling with Dynamic Object-Oriented Bayesian Networks (DOOBN). Reliability Engineering and System Safety, 91(2), 149-162.

WindEurope. (2019). Wind energy in Europe in 2018: Trends and statistics, 30 pages. Available at: https:/windeurope.org/wp-content/uploads/files/about-wind/statistics/WindEurope-Annual-Statistics2018.pdf. (accessed on 18.03.2019)

Xie, W., Zhang, P., Chen, R., and Zhou, Z. (2019). A nonparametric Bayesian framework for short-term wind power probabilistic forecast. IEEE Transactions on Power Systems, 34(1), 371-379.

Yang, D.Y. and Frangopol, D.M. (2018). Evidence-based framework for real-time life-cycle management of fatigue-critical details of structures. Structure and Infrastructure Engineering, 14(5), 509-522.

Yang, X., Fu, G., Zhang, Y., Kang, N., and Gao, F. (2017). A Naive Bayesian wind power interval prediction approach based on rough set attribute reduction and weight optimization. Energies, 10(11), 15 pages. https://doi.org/10.3390/en10111903.

Zhong, J.H., Zhang, J., Liang, J., and Wang, H. (2019). Multi-fault rapid diagnosis for wind turbine gearbox using sparse Bayesian extreme learning machine. IEEE Access, 7(1), 773-781.

Ziegler, L. (2018). Assessment of monopiles for lifetime extension of offshore wind turbines. $\mathrm{PhD} \mathrm{Thesis,}$ Norwegian University of Science and Technology, Trondheim, Norway. 


\section{APPENDIX}

Table A. A detailed analysis of the reviewed studies about BN application in wind energy.

\begin{tabular}{|c|c|c|c|c|c|c|c|c|}
\hline Reference & Year & $\begin{array}{l}\text { Mathematical } \\
\text { Problem }\end{array}$ & Input & Output & Specifications & Challenges of solution & Advantages & Limitations \\
\hline Cheng et al. & 2002 & $\begin{array}{l}\text { Estimation of } \\
\text { uncertainties in } \\
\text { displacement of WT } \\
\text { blades }\end{array}$ & 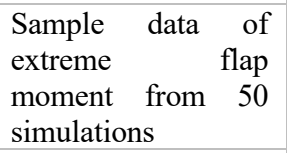 & $\begin{array}{l}100 \text {-year estimate of } \\
\text { blade response using } \\
\text { different distribution } \\
\text { functions }\end{array}$ & $\begin{array}{l}\text { Bayesian Averaging (BA) } \\
\text { method is used }\end{array}$ & $\begin{array}{l}\text { Simulation results still have to } \\
\text { be analysed statistically }\end{array}$ & $\begin{array}{l}\text { Compared to Maximum } \\
\text { deflection theory, BN } \\
\text { produced more accurate } \\
\text { results }\end{array}$ & $\begin{array}{l}\text { Data was obtained } \\
\text { from simulations and } \\
\text { not real measurements }\end{array}$ \\
\hline $\begin{array}{l}\text { Garbatov } \\
\text { and Soares }\end{array}$ & 2002 & $\begin{array}{l}\text { Bayesian updates of } \\
\text { model parameters } \\
\text { for floating structure } \\
\text { fatigue reliability } \\
\text { assessment }\end{array}$ & $\begin{array}{l}\text { Material constants, } \\
\text { initial crack size, } \\
\text { geometry parameter }\end{array}$ & $\begin{array}{l}\text { Posterior probability } \\
\text { function of time to } \\
\text { crack initiation, and } \\
\text { reliability of } \\
\text { structure }\end{array}$ & $\begin{array}{l}\text { Uncertainties are } \\
\text { associated with time to } \\
\text { crack initiation, inspection } \\
\text { quality and material } \\
\text { properties }\end{array}$ & $\begin{array}{l}\text { There is a need to improve } \\
\text { reliability analysis techniques } \\
\text { by considering anticipated } \\
\text { degradation and accounting } \\
\text { for estimation uncertainties }\end{array}$ & $\begin{array}{l}\text { Bayesian updating improves } \\
\text { O\&M decision-making } \\
\text { based on system reliability }\end{array}$ & $\begin{array}{l}\text { Accuracy of BN } \\
\text { updating method } \\
\text { depends on the } \\
\text { posterior function } \\
\text { used for the estimation }\end{array}$ \\
\hline $\begin{array}{l}\text { Rangel- } \\
\text { Ramírez and } \\
\text { Sørensen }\end{array}$ & 2009 & $\begin{array}{l}\text { Integration of } \mathrm{CM} \\
\text { with } \mathrm{BN} \text { inference }\end{array}$ & $\begin{array}{l}\text { Model uncertainty } \\
\text { from wind load } \\
\text { effects, posterior } \\
\text { density function, } \\
\text { design parameters }\end{array}$ & $\begin{array}{l}\text { Accumulated } \\
\text { reliability index, } \\
\text { lifecycle reliability, } \\
\text { RBI information }\end{array}$ & $\begin{array}{l}\text { Fatigue prone hot-spots on } \\
\text { WT support structures are } \\
\text { analysed. Reliability is } \\
\text { assessed by the S-N } \\
\text { approach }\end{array}$ & $\begin{array}{l}\text { Offshore WFs require } \\
\text { improved maintenance } \\
\text { planning methods due to the } \\
\text { extreme conditions }\end{array}$ & $\begin{array}{l}\text { Inspection plans are updated } \\
\text { with better informed } \\
\text { reliability data }\end{array}$ & N.A \\
\hline Sørensen & 2009 & $\begin{array}{l}\text { CBM using pre- } \\
\text { posterior Bayesian } \\
\text { decision theory }\end{array}$ & $\begin{array}{l}\text { Updated damage } \\
\text { accumulation } \\
\text { model, Design } \\
\text { parameters }\end{array}$ & $\begin{array}{l}\text { Probability of } \\
\text { failure at a particular } \\
\text { time, overall O\&M } \\
\text { cost }\end{array}$ & $\begin{array}{l}\text { Lifetime probability of } \\
\text { failure for WT gearbox } \\
\text { was simulated using } \\
\text { FORM software }\end{array}$ & $\begin{array}{l}\text { It is complicated to calculate } \\
\text { costs, failure rates, and } \\
\text { damage models for WT } \\
\text { gearbox }\end{array}$ & $\begin{array}{l}\text { Risk-based } \\
\text { method can be used to make } \\
\text { decisions under uncertain } \\
\text { conditions }\end{array}$ & N.A. \\
\hline Li and Shi & 2010 & $\begin{array}{l}\text { Wind speed } \\
\text { modelling with } \\
\text { taking into account } \\
\text { parameter and } \\
\text { model uncertainties }\end{array}$ & $\begin{array}{lr}2 \text {-year wind } & \text { speed } \\
\text { records at } 10 \mathrm{~m} \\
\text { height, } & \text { prior } \\
\text { distributions } & \text { for } \\
\text { each parameter } & \end{array}$ & $\begin{array}{l}\text { Posterior mean and } \\
\text { variance of BMA } \\
\text { predictions given } \\
\text { the observed data }\end{array}$ & $\begin{array}{l}\text { WinBUGS is used to } \\
\text { obtain the parameter } \\
\text { samples for the prior } \\
\text { distribution. BMA and } \\
\text { MCMC are used for wind } \\
\text { speed distributions }\end{array}$ & $\begin{array}{l}\text { Conventional statistical } \\
\text { models are not applicable as } \\
\text { they only focus on parameter } \\
\text { uncertainty but not model } \\
\text { uncertainty }\end{array}$ & $\begin{array}{l}\text { The uncertainty can be } \\
\text { better accounted for by } \\
\text { using an averaged model. } \\
\text { BMA produced more robust } \\
\text { long-term wind speed } \\
\text { distributions for all sites }\end{array}$ & $\begin{array}{l}\text { Candidate models still } \\
\text { need to be selected to } \\
\text { perform BMA. It is } \\
\text { difficult to visually } \\
\text { analyse plots from } \\
\text { BMA }\end{array}$ \\
\hline $\begin{array}{l}\text { Nielsen and } \\
\text { Sørensen }\end{array}$ & $2010 \mathrm{a}$ & $\begin{array}{l}\text { Damage size and } \\
\text { failure probability } \\
\text { updating with new } \\
\text { information for RBI } \\
\text { planning using BN }\end{array}$ & $\begin{array}{l}\text { Wind load, prior } \\
\text { distribution of } \\
\text { number of cycles, } \\
\text { material parameters, } \\
\text { load measurements }\end{array}$ & $\begin{array}{l}\text { Failure } \\
\text { probabilities, } \\
\text { posterior } \\
\text { distribution } \\
\text { damage size }\end{array}$ & $\begin{array}{l}\text { It generates } 30,000 \\
\text { samples to calculate } \\
\text { posterior distribution. } \\
\text { Damage sizes are entered } \\
\text { annually in the model }\end{array}$ & $\begin{array}{l}\text { Damage models are used to } \\
\text { describe } \\
\text { development. The uncertain } \\
\text { parameters are described using } \\
\text { stochastic models }\end{array}$ & $\begin{array}{l}\text { Incorporating inspection } \\
\text { results and load monitoring } \\
\text { produces more reliable } \\
\text { damage models and failure } \\
\text { estimates }\end{array}$ & N.A. \\
\hline $\begin{array}{l}\text { Nielsen and } \\
\text { Sørensen }\end{array}$ & $2010 b$ & $\begin{array}{l}\text { Probabilistic } \\
\text { modelling to update } \\
\text { damage size / failure } \\
\text { probability with } \\
\mathrm{CM} / \text { inspection data }\end{array}$ & $\begin{array}{l}\text { SCADA data, wind } \\
\text { loads }\end{array}$ & $\begin{array}{l}\text { Updated failure } \\
\text { probability, damage } \\
\text { size estimates, } \\
\text { expected annual cost } \\
\text { of repair }\end{array}$ & $\begin{array}{l}\text { Only fatigue cracking } \\
\text { failure mechanism is } \\
\text { considered. Crack } \\
\text { propagation follows Paris' } \\
\text { law }\end{array}$ & $\begin{array}{l}\text { Damage models have many } \\
\text { uncertainties which have to be } \\
\text { quantified for more reliable } \\
\text { and accurate damage size } \\
\text { estimation }\end{array}$ & $\begin{array}{l}\text { Incorporating } \mathrm{CM} \text { and } \\
\text { inspection results improves } \\
\text { the accuracy of reliability } \\
\text { estimations }\end{array}$ & N.A. \\
\hline
\end{tabular}




\begin{tabular}{|c|c|c|c|c|c|c|c|c|}
\hline $\begin{array}{l}\text { Sloughter et } \\
\text { al. }\end{array}$ & 2010 & $\begin{array}{l}\text { Explicit wind speed } \\
\text { modelling of full } \\
\text { predictive }\end{array}$ & $\begin{array}{l}\text { Wind speed dataset } \\
\text { of observation } \\
\text { stations }\end{array}$ & $\begin{array}{l}\text { Verification rank for } \\
\text { a raw ensemble } \\
\text { forecast histogram } \\
\text { and probability } \\
\text { integral transform } \\
\text { (PIT) histogram }\end{array}$ & $\begin{array}{l}\text { Data is available for } 340 \\
\text { days from } 35,230 \text { station } \\
\text { observations. Discretised } \\
\text { wind speed data is } \\
\text { rounded to the nearest } \\
\text { whole knot }\end{array}$ & $\begin{array}{l}\text { When sparse data is available, } \\
\text { fitting of predictive PDF is } \\
\text { challenging }\end{array}$ & $\begin{array}{l}\text { BMA produces bias- } \\
\text { corrected forecasts. It can } \\
\text { produce } 48 \text {-hour ahead wind } \\
\text { speed forecasts by } \\
\text { improving predictive PDF } \\
\text { sharpness }\end{array}$ & $\begin{array}{l}\text { BMA may not } \\
\text { perform well if there is } \\
\text { substantial topography } \\
\text { at sub-grid scales }\end{array}$ \\
\hline $\begin{array}{l}\text { Sørensen } \\
\text { and Toft }\end{array}$ & 2010 & $\begin{array}{l}\text { Use of probabilistic } \\
\text { models and } \\
\text { reliability estimates } \\
\text { to improve design } \\
\text { based on new test } \\
\text { information }\end{array}$ & $\begin{array}{l}\text { Design variables } \\
\text { (rotor height, tower } \\
\text { diameter and } \\
\text { thickness, } \\
\text { foundation radius, } \\
\text { etc.), stochastic } \\
\text { variables (maximum } \\
\text { wind pressure, } \\
\text { turbulence intensity) }\end{array}$ & $\begin{array}{l}\text { WT design is } \\
\text { optimised based on } \\
\text { reliability levels. } \\
\text { The damage at } \\
\text { failure is estimated } \\
\text { during amplitude } \\
\text { testing }\end{array}$ & $\begin{array}{l}\text { An integrated uncertainty } \\
\text { modelling is proposed for } \\
\text { optimum WT design based } \\
\text { on optimal reliability } \\
\text { estimates. Application } \\
\text { case study was a model for } \\
\text { local buckling failure of } \\
\text { support structures }\end{array}$ & $\begin{array}{l}\text { Uncertainties must be } \\
\text { incorporated into WT design }\end{array}$ & $\begin{array}{l}\text { Test results and uncertainty } \\
\text { can be included in the design } \\
\text { process. Both physical and } \\
\text { statistical uncertainty and } \\
\text { expert judgement can be } \\
\text { incorporated into the design }\end{array}$ & N.A. \\
\hline Ye et al. & 2010 & $\begin{array}{l}\text { Improved fault } \\
\text { detection using three } \\
\text { tests to detect the } \\
\text { system states }\end{array}$ & $\begin{array}{l}\text { SCADA data, power } \\
\text { output, rotor speed, } \\
\text { blade pitch angle }\end{array}$ & $\begin{array}{l}\text { WT performance } \\
\text { features }\end{array}$ & $\begin{array}{l}\text { Tests from the Multi- } \\
\text { dimensional Scaling } \\
\text { (MDS) method are used as } \\
\text { inputs to BN for improved } \\
\text { decision-making }\end{array}$ & N.A. & $\begin{array}{l}\text { This method produces better } \\
\text { fault detection results } \\
\text { because different matrices } \\
\text { are used in the fault } \\
\text { detection }\end{array}$ & N.A. \\
\hline Blonbou & 2011 & $\begin{array}{l}\text { Short term }(15- \\
\text { minute ahead) wind } \\
\text { power prediction } \\
\text { using adaptive } \\
\text { Bayesian learning }\end{array}$ & $\begin{array}{l}\text { Wind speed data, } \\
\text { wind power } \\
\text { production data }\end{array}$ & $\begin{array}{l}\text { Future values of } \\
\text { electrical power } \\
\text { generated }\end{array}$ & $\begin{array}{l}\text { Wind speed and power } \\
\text { production are measured } \\
\text { at sampling rate of } 1 \mathrm{~Hz} . \\
\text { Neural networks are } \\
\text { trained with Bayesian } \\
\text { procedure }\end{array}$ & N.A. & $\begin{array}{l}\text { Bayesian framework helps } \\
\text { to forecast the interval } \\
\text { within which generated } \\
\text { power should be observed. It } \\
\text { allows for control of the } \\
\text { network complexity }\end{array}$ & N.A. \\
\hline Carta et al. & 2011 & $\begin{array}{l}\text { Estimation of long- } \\
\text { term wind speed } \\
\text { frequency } \\
\text { distribution for a } \\
\text { WF site with limited } \\
\text { measurements }\end{array}$ & $\begin{array}{l}\text { 10-year mean hourly } \\
\text { wind speed and } \\
\text { direction data from } 4 \\
\text { weather stations }\end{array}$ & $\begin{array}{l}\text { Cumulative relative } \\
\text { frequency histogram } \\
\text { of wind speed, mean } \\
\text { wind power density, } \\
\text { mean annual energy } \\
\text { output }\end{array}$ & $\begin{array}{l}\text { Two commercial WTs of } \\
330 \text { and } 800 \mathrm{~kW} \text { were } \\
\text { chosen. Model evaluation } \\
\text { technique uses 10-fold } \\
\text { (cross-validation) method } \\
\text { to evaluate the errors }\end{array}$ & $\begin{array}{l}\text { Insufficient data makes it } \\
\text { difficult to predict wind } \\
\text { behaviours at WF sites. }\end{array}$ & $\begin{array}{l}\text { Allows for the use of wind } \\
\text { speed data from different } \\
\text { reference stations. Less error } \\
\text { between real and estimated } \\
\text { energy outputs is obtained }\end{array}$ & N.A. \\
\hline $\begin{array}{l}\text { Chen and } \\
\text { Hao }\end{array}$ & 2011 & $\begin{array}{ll}\text { Gearbox } & \text { fault } \\
\text { diagnosis } & \end{array}$ & $\begin{array}{l}\text { Sample data, types } \\
\text { of fault (e.g. tooth } \\
\text { profile error, broken } \\
\text { gear tooth, shaft } \\
\text { imbalance, etc.), } \\
\text { fault feature }\end{array}$ & $\begin{array}{l}\text { Marginal probability } \\
\text { density of a fault } \\
\text { node }\end{array}$ & $\begin{array}{l}\text { Sample data is described } \\
\text { by a } n \text {-dimensional vector. } \\
\text { Fault features, e.g. RMS, } \\
\text { kurtosis, mean are selected } \\
\text { and BN is used to calculate } \\
\text { the conditional probability }\end{array}$ & $\begin{array}{l}\text { There are six forms of fault in } \\
\text { WT gearbox and it is difficult } \\
\text { to correctly recognise and } \\
\text { diagnose these faults using } \\
\text { traditional methods }\end{array}$ & $\begin{array}{l}\text { Less computation time, } \\
\text { good convergence and } \\
\text { strong real-time property. } \\
\text { State identification and fault } \\
\text { diagnosis under uncertainty } \\
\text { can be made with BN }\end{array}$ & N.A. \\
\hline $\begin{array}{l}\text { Nielsen and } \\
\text { Sørensen }\end{array}$ & 2011 & $\begin{array}{lr}\text { Optimal } & \text { O\&M } \\
\text { planning } & \text { based on } \\
\text { Bayesian } & \text { pre- } \\
\text { posterior } & \text { decision } \\
\text { theory } & \end{array}$ & $\begin{array}{l}\text { Weather data, } \\
\text { failure rate data }\end{array}$ & $\begin{array}{l}\text { Framework for } \\
\text { reliability modelling } \\
\text { of WT blades }\end{array}$ & $\begin{array}{l}\text { A decision is made on } \\
\text { when and how to maintain } \\
\text { and repair } \text { WT } \\
\text { components. Damage }\end{array}$ & $\begin{array}{l}\text { Corrective maintenance in } \\
\text { O\&M is flawed because it may } \\
\text { lead to failures occurring at } \\
\text { times of limited accessibility } \\
\text { to the assets }\end{array}$ & $\begin{array}{l}\text { Information from NDI } \\
\text { techniques can be used to } \\
\text { update reliability model } \\
\text { using Bayesian methods }\end{array}$ & N.A. \\
\hline
\end{tabular}




\begin{tabular}{|c|c|c|c|c|c|c|c|c|}
\hline & & & & & $\begin{array}{l}\text { models are associated with } \\
\text { uncertainties }\end{array}$ & & & \\
\hline Toft et al. & 2011 & $\begin{array}{l}\text { Updating reliability } \\
\text { assessments with } \\
\text { NDI data from WT } \\
\text { blades using BN }\end{array}$ & $\begin{array}{l}\text { Data from blade } \\
\text { NDI }\end{array}$ & $\begin{array}{l}\text { Updated reliability } \\
\text { or probability of } \\
\text { failure }\end{array}$ & $\begin{array}{l}\text { Defect positions are } \\
\text { generated randomly } \\
\text { within the model. Defects } \\
\text { are repaired when detected }\end{array}$ & $\begin{array}{l}\text { NDI techniques are still prone } \\
\text { to many uncertainties }\end{array}$ & $\begin{array}{l}\text { Reliability can be improved } \\
\text { by updating with NDI } \\
\text { information }\end{array}$ & $\begin{array}{l}\text { The reliability is } \\
\text { dependent on POD of } \\
\text { the NDI technique } \\
\text { used for inspection }\end{array}$ \\
\hline $\begin{array}{l}\text { Toft and } \\
\text { Sørensen }\end{array}$ & 2011 & $\begin{array}{l}\text { Probabilistic design } \\
\text { and reliability } \\
\text { updating of WT } \\
\text { blades with test data } \\
\text { using BN and ML } \\
\text { methods }\end{array}$ & $\begin{array}{lr}\text { Material } r & \text { strength } \\
\text { coefficient } & \text { of } \\
\text { variation, number of } \\
\text { tests }\end{array}$ & $\begin{array}{l}\text { Reliability index in a } \\
\text { year given number } \\
\text { of tests }\end{array}$ & $\begin{array}{l}\text { Bayesian method was used } \\
\text { to estimate ULS function. } \\
\text { Only one failure mode was } \\
\text { considered in the } \\
\text { reliability estimation }\end{array}$ & $\begin{array}{l}\text { Design uncertainties are } \\
\text { inherent in WT blades. Full- } \\
\text { scale tests contain } \\
\text { uncertainties }\end{array}$ & $\begin{array}{l}\text { Estimation of uncertainty of } \\
\text { material strength is possible } \\
\text { even with little test data. } \\
\text { Data from past full-scale } \\
\text { tests may be used for prior } \\
\text { data used in the analysis }\end{array}$ & $\begin{array}{l}\text { The Bayesian method } \\
\text { is dependent on the } \\
\text { number and quality of } \\
\text { prior test data }\end{array}$ \\
\hline Chen et al. & 2013 & $\begin{array}{l}\text { Detection and } \\
\text { location of faults }\end{array}$ & $\begin{array}{l}\text { SCADA data, } \\
\text { outputs from a Venn } \\
\text { diagram analysis }\end{array}$ & $\begin{array}{l}\text { Fault probability, } \\
\text { root causes } \\
\text { depending on the } \\
\text { input data }\end{array}$ & $\begin{array}{l}\text { The BN modelled the } \\
\text { relationships between the } \\
\text { condition of pitch system } \\
\text { and sensor readings. } \\
\text { SCADA data was used to } \\
\text { train the BN }\end{array}$ & $\begin{array}{l}\text { There is a gap for automatic } \\
\text { use of SCADA data in failure } \\
\text { diagnosis }\end{array}$ & $\begin{array}{l}\text { BNs can make inference } \\
\text { about the probabilities of all } \\
\text { connected events. The } \\
\text { sensor readings are collected } \\
\text { online and used to update the } \\
\text { BN in fault diagnosis }\end{array}$ & $\begin{array}{l}\text { BN can become too } \\
\text { complex. The } \\
\text { accuracy of the BN } \\
\text { model depends on the } \\
\text { quantity of input data }\end{array}$ \\
\hline $\begin{array}{l}\text { Plumley et } \\
\text { al. }\end{array}$ & 2012 & $\begin{array}{l}\text { Degradation } \\
\text { modelling of WT } \\
\text { systems } r \text { to } \\
\text { determine optimal } \\
\text { O\&M }\end{array}$ & N.A. & $\begin{array}{lr}\text { Probability } & \text { density } \\
\text { functions } & \text { and } \\
\text { updates } & \end{array}$ & $\begin{array}{l}\text { The BN was tested by } \\
\text { running different failure } \\
\text { mode scenarios using } \\
\text { changes in temperature } \\
\text { and metal particles within } \\
\text { the lubricant. LabVIEW } \\
\text { was used to show how } \\
\text { BNs can be used. }\end{array}$ & $\begin{array}{l}\text { Although condition } \\
\text { monitoring systems are } \\
\text { effective, false positives } \\
\text { increase O\&M cost. Thus, a } \\
\text { method is required to improve } \\
\text { the accuracy and robustness of } \\
\text { the results }\end{array}$ & $\begin{array}{l}\text { BN allows evidence to be } \\
\text { propagated in the model in } \\
\text { order to update the posterior } \\
\text { probability of the model }\end{array}$ & N.A. \\
\hline $\begin{array}{l}\text { Fernández- } \\
\text { Cantí et al. }\end{array}$ & 2013 & $\begin{array}{l}\text { Non-linear set } \\
\text { membership model } \\
\text { estimation and fault } \\
\text { detection }\end{array}$ & N.A. & $\begin{array}{l}\text { Feasible dataset and } \\
\text { verification that } \\
\text { model matches } \\
\text { dataset }\end{array}$ & $\begin{array}{l}\text { The faults of pitch system } \\
\text { were detected using } 50000 \\
\text { sample data generated by a } \\
\text { Simulink model }\end{array}$ & $\begin{array}{l}\text { There are some challenges for } \\
\text { executing } \quad \text { Bayesian } \\
\text { estimations }\end{array}$ & $\begin{array}{l}\text { The Bayesian set- } \\
\text { membership approach } \\
\text { requires less run-time than } \\
\text { statistical methods }\end{array}$ & N.A. \\
\hline Lee et al. & 2013 & $\begin{array}{lr}\text { Wind } & \text { turbine } \\
\text { extreme } & \text { load } \\
\text { estimation } & \end{array}$ & N.A. & N.A. & $\begin{array}{l}\text { Bayesian spline method is } \\
\text { used to extrapolate } \\
\text { extreme loading response } \\
\text { of WTs. The results are } \\
\text { compared with the binning } \\
\text { method of load estimation }\end{array}$ & $\begin{array}{l}\text { The binning method cannot } \\
\text { accurately estimate the } \\
\text { uncertainty of extreme loads. } \\
\text { When the binning method is } \\
\text { used, there is an overestimate } \\
\text { of the extreme loading on WT }\end{array}$ & $\begin{array}{l}\text { The Bayesian spline method } \\
\text { produces less parameters } \\
\text { than the binning method for } \\
\text { extremer response } \\
\text { estimation. It is also more } \\
\text { flexible in data handling }\end{array}$ & N.A. \\
\hline $\begin{array}{l}\text { Mardfekri } \\
\text { and Gardoni }\end{array}$ & 2013 & $\begin{array}{l}\text { Fragility estimation } \\
\text { for a WT support } \\
\text { structure using } \\
\text { probabilistic models }\end{array}$ & $\begin{array}{l}\text { Deformation } \\
\text { capacity, shear } \\
\text { capacity (yield } \\
\text { stress and ultimate } \\
\text { stress), wind speed, } \\
\text { wave height }\end{array}$ & $\begin{array}{l}\text { Fragility estimates } \\
\text { (in relation to } \\
\text { serviceability, yield } \\
\text { and ultimate limits) } \\
\text { based on wind speed }\end{array}$ & $\begin{array}{l}\text { Fragility estimates were } \\
\text { developed for three failure } \\
\text { modes: drift, shear and } \\
\text { bending failure, based on } \\
\text { the wave heights at } \\
\text { different wind speeds }\end{array}$ & $\begin{array}{l}\text { Deterministic methods do not } \\
\text { account for uncertainties and } \\
\text { have inherent biases }\end{array}$ & $\begin{array}{l}\text { Bayesian methods can } \\
\text { update the model based on } \\
\text { newer information from } \\
\text { FEA of the structure }\end{array}$ & N.A. \\
\hline
\end{tabular}




\begin{tabular}{|c|c|c|c|c|c|c|c|c|}
\hline $\begin{array}{l}\text { Van Buren } \\
\text { et al. }\end{array}$ & 2013 & $\begin{array}{l}\text { Reduction of model } \\
\text { uncertainty in WT } \\
\text { blade dynamics } \\
\text { modelling }\end{array}$ & $\begin{array}{l}\text { FE model } \\
\text { parameters (trailing } \\
\text { edge, spar cap and Z } \\
\text { spring) }\end{array}$ & $\begin{array}{l}\text { Posterior predictions } \\
\text { of the blade model }\end{array}$ & $\begin{array}{l}\text { The posterior probabilities } \\
\text { of five parameters were } \\
\text { obtained }\end{array}$ & N.A. & $\begin{array}{l}\text { Parameter uncertainty can } \\
\text { be included in the model } \\
\text { using Bayesian inference }\end{array}$ & N.A. \\
\hline Wang et al. & 2013 & $\begin{array}{l}\text { Identification of } \\
\text { uncertain and fuzzy } \\
\text { vibrational } \\
\text { generator fault } \\
\text { signals }\end{array}$ & $\begin{array}{l}\text { Data about } \\
\text { generator state }\end{array}$ & $\begin{array}{l}\text { Failure rate of } \\
\text { generator, } \\
\text { mechanical drive } \\
\text { system }\end{array}$ & $\begin{array}{l}\text { Feature recognition and } \\
\text { Bayesian methods are } \\
\text { used to detect faults. The } \\
\text { BN structure is created } \\
\text { with the fault symptoms } \\
\text { and fault layer. }\end{array}$ & $\begin{array}{l}\text { Conventional methods cannot } \\
\text { accurately identify fault types } \\
\text { and their location in generator }\end{array}$ & $\begin{array}{l}\text { BN has the capacity to } \\
\text { estimate system reliability } \\
\text { under uncertainty }\end{array}$ & $\begin{array}{l}\text { Bayesian inference } \\
\text { quality is dependent } \\
\text { on an accurate } \\
\text { selection of fault } \\
\text { signal events }\end{array}$ \\
\hline García et al. & 2014 & $\begin{array}{l}\text { Wind power } \\
\text { forecasting using } \\
\text { DBN for more than } \\
5 \text { hours ahead }\end{array}$ & $\begin{array}{l}\text { 2-year wind farm } \\
\text { data, including: } \\
\text { wind speed and } \\
\text { direction, } \\
\text { temperature, } \\
\text { humidity, pressure }\end{array}$ & $\begin{array}{lr}\text { Wind } & \text { power } \\
\text { forecasts from the } \\
\text { BN are compared } \\
\text { with time-series } \\
\text { method }\end{array}$ & $\begin{array}{l}\text { 10-minute input data is } \\
\text { used for training and } \\
\text { testing the model }\end{array}$ & $\begin{array}{l}\text { Classical techniques of wind } \\
\text { power forecasting do not } \\
\text { account for many variables. } \\
\text { Thus, their precision is limited }\end{array}$ & $\begin{array}{l}\text { Methodology for DBN can } \\
\text { be used for different } \\
\text { forecasting problems. The } \\
\text { average error is more } \\
\text { acceptable than with other } \\
\text { techniques }\end{array}$ & $\begin{array}{l}\text { Daily variable data are } \\
\text { not considered }\end{array}$ \\
\hline $\begin{array}{l}\text { Nielsen and } \\
\text { Sørensen }\end{array}$ & 2014 & $\begin{array}{l}\text { O\&M decision } \\
\text { updating }\end{array}$ & N.A. & $\begin{array}{l}\text { Optimal } \\
\text { decision }\end{array}$ & $\begin{array}{l}\text { Probability of failure and } \\
\text { accuracy of monitoring } \\
\text { results are calculated }\end{array}$ & $\begin{array}{l}\text { The decisions about repair } \\
\text { affect the associated costs of } \\
\text { O\&M. A method for O\&M } \\
\text { updating is required }\end{array}$ & $\begin{array}{l}\text { Pre-posterior decision } \\
\text { analysis using Bayesian } \\
\text { methods can be used to } \\
\text { determine the best O\&M } \\
\text { planning option }\end{array}$ & $\begin{array}{l}\text { Approximation } \\
\text { techniques still need to } \\
\text { be used in Bayesian } \\
\text { analysis }\end{array}$ \\
\hline $\mathrm{Su}$ and $\mathrm{Fu}$ & 2014 & $\begin{array}{lr}\text { Reliability model } \\
\text { using BN } \text { to } \\
\text { incorporate } \\
\text { uncertain } \\
\text { speed effects }\end{array}$ & $\begin{array}{l}10 \text {-year failure data } \\
\text { records }\end{array}$ & $\begin{array}{l}\text { Reliability of WT } \\
\text { with varying speed }\end{array}$ & $\begin{array}{l}\text { BN is mapped from a WT } \\
\text { submodule fault tree. } \\
\text { AgenaRisk tool was used } \\
\text { for model reliability }\end{array}$ & $\begin{array}{l}\text { Conventional reliability } \\
\text { estimation methods do not } \\
\text { account for component } \\
\text { interrelationships } \\
\text { dynamic wind speed }\end{array}$ & $\begin{array}{l}\text { The BN method includes the } \\
\text { advantages of fault tree, } \\
\text { uncertainty and } \\
\text { environmental factor impact }\end{array}$ & N.A. \\
\hline $\begin{array}{l}\text { Bracale and } \\
\text { De Falco }\end{array}$ & 2015 & $\begin{array}{l}\text { Improved accuracy } \\
\text { in wind power } \\
\text { forecasting with a } \\
\text { Bayesian method }\end{array}$ & $\begin{array}{l}\text { Shape and scale } \\
\text { parameters for the } \\
\text { wind } \\
\text { distribution speed }\end{array}$ & $\begin{array}{l}\text { More accurate time } \\
\text { series model }\end{array}$ & $\begin{array}{l}\text { A mixture Weibull } \\
\text { distribution (MWD) was } \\
\text { used to model the wind } \\
\text { speed }\end{array}$ & $\begin{array}{l}\text { Uncertainties associated with } \\
\text { the wind power resource } \\
\text { availability were modelled by } \\
\text { probabilistic methods }\end{array}$ & $\begin{array}{l}\text { Probabilistic wind power } \\
\text { forecasting is improved with } \\
\text { Bayesian inference with } \\
\text { incorporating changing } \\
\text { environmental conditions }\end{array}$ & $\begin{array}{l}\text { The model used the } \\
\text { deterministic power } \\
\text { curve provided by the } \\
\text { WT OEM }\end{array}$ \\
\hline $\begin{array}{l}\text { Fernández- } \\
\text { Cantí et al. }\end{array}$ & 2015 & \begin{tabular}{lr}
\multicolumn{2}{l}{ Fault detection and } \\
isolation & using \\
Bayesian & set- \\
membership & \\
approach &
\end{tabular} & $\begin{array}{l}\text { Residuals, fault } \\
\text { indicator vector and } \\
\text { associated indexes }\end{array}$ & $\begin{array}{l}\text { Distributions for the } \\
\text { residuals, posterior } \\
\text { probabilities of } \\
\text { different fault } \\
\text { scenarios given the } \\
\text { alpha-coefficients }\end{array}$ & $\begin{array}{l}\text { The errors in the model are } \\
\text { bounded by the Bayesian } \\
\text { Set-membership } \\
\text { framework }\end{array}$ & $\begin{array}{l}\text { Other models use very large } \\
\text { detection thresholds, which } \\
\text { increase the likelihood of false } \\
\text { detections }\end{array}$ & $\begin{array}{l}\text { The method combined the } \\
\text { advantages of reduction in } \\
\text { model error and false } \\
\text { positive. False alarms were } \\
\text { reduced. There was an } \\
\text { improved detection time }\end{array}$ & N.A. \\
\hline $\begin{array}{l}\text { Kougioumtz } \\
\text { oglou and } \\
\text { Lazakis }\end{array}$ & 2015 & 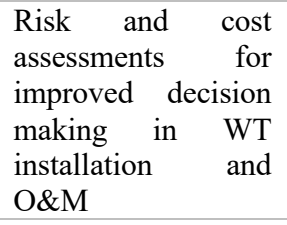 & $\begin{array}{lr}\begin{array}{l}\text { Probability } \\
\text { failure }\end{array} & \begin{array}{r}\text { of } \\
\text { (from }\end{array} \\
\text { OREDA Handbook) }\end{array}$ & $\begin{array}{l}\text { FMECA and } \\
\text { HAZID matrix, total } \\
\text { probability of } \\
\text { failure, total cost of } \\
\text { failure }\end{array}$ & $\begin{array}{l}\text { The most critical } \\
\text { components of WTs were } \\
\text { identified. BN was used } \\
\text { for the risk assessment and } \\
\text { cost analysis for WT } \\
\text { O\&M strategy }\end{array}$ & $\begin{array}{l}\text { In order to incorporate all risk } \\
\text { factors and model uncertainty, } \\
\text { a more robust tool has to be } \\
\text { developed }\end{array}$ & $\begin{array}{l}\text { BNs can be used for HAZID } \\
\text { analysis and include the } \\
\text { utility (cost) associated for } \\
\text { most critical events }\end{array}$ & N.A. \\
\hline
\end{tabular}




\begin{tabular}{|c|c|c|c|c|c|c|c|c|}
\hline Li et al. & 2015 & $\begin{array}{l}\text { Reliability } \\
\text { assessment of WTs }\end{array}$ & $\begin{array}{l}\text { Initial conditional } \\
\text { probabilities of WT } \\
\text { states }\end{array}$ & $\begin{array}{l}\text { Predicted WT state } \\
\text { and absolute error }\end{array}$ & $\begin{array}{l}\text { BN was used to validate } \\
\text { the proposed Goal Tree, } \\
\text { Success Tree and Master } \\
\text { Logic Diagram (GTST- } \\
\text { MLD). BN was modelled } \\
\text { in MSBNx }\end{array}$ & $\begin{array}{l}\text { Conventional reliability } \\
\text { models do not account for } \\
\text { logical and functional } \\
\text { relationship between WT } \\
\text { components }\end{array}$ & N.A. & N.A. \\
\hline $\begin{array}{l}\text { Mardfekri } \\
\text { and Gardoni }\end{array}$ & 2015 & $\begin{array}{l}\text { WT structural } \\
\text { performance } \\
\text { assessment in the } \\
\text { event of multiple } \\
\text { hazards }\end{array}$ & $\begin{array}{l}\text { Virtual experiment } \\
\text { data (obtained from } \\
\text { FEM in extreme } \\
\text { wind and seismic } \\
\text { loads), spectral } \\
\text { acceleration, wind } \\
\text { speed }\end{array}$ & $\begin{array}{l}\text { Estimation of } \\
\text { fragility (as a } \\
\text { function of spectral } \\
\text { acceleration and } \\
\text { mean wind speed), } \\
\text { annual probabilities } \\
\text { of structural damage }\end{array}$ & $\begin{array}{l}\text { MCS is used to estimate } \\
\text { the fragility of WT support } \\
\text { structures. All potential } \\
\text { hazards are taken into } \\
\text { account. Probabilistic } \\
\text { seismic demand models } \\
\text { are updated. }\end{array}$ & $\begin{array}{l}\text { There are few works taking } \\
\text { foundation stiffness into } \\
\text { account in WT structural } \\
\text { response. The conventional } \\
\text { models are computationally } \\
\text { expensive and may produce } \\
\text { inaccurate structural responses }\end{array}$ & $\begin{array}{l}\text { This assessment can help } \\
\text { decision makers optimally } \\
\text { design WTs. Uncertainties } \\
\text { can be incorporated to } \\
\text { reduce result bias. Faster } \\
\text { processing time with } \\
\text { improved accuracy }\end{array}$ & N.A. \\
\hline Pan et al. & 2015 & $\begin{array}{l}\text { Presentation of } \\
\text { errors in } \\
\text { probabilistic wind } \\
\text { power forecasting }\end{array}$ & $\begin{array}{l}\text { Wind speed, wind } \\
\text { direction, } \\
\text { temperature, air } \\
\text { pressure } \\
\text { humidity }\end{array}$ & $\begin{array}{l}\text { Predicted wind } \\
\text { power curve }\end{array}$ & $\begin{array}{l}\text { Sparse Bayesian Learning } \\
\text { (SBL) is used to develop a } \\
\text { probabilistic forecasting } \\
\text { method for wind power. } \\
\text { Parameters of the kernel } \\
\text { functions are optimised in } \\
\text { order to improve SBL } \\
\text { model by using the } \\
\text { modified-Gaussian kernel } \\
\text { function and Particle Swan } \\
\text { Optimisation (PSO) }\end{array}$ & $\begin{array}{l}\text { Probabilistic models focused } \\
\text { on non-parametric methods, } \\
\text { which need more data and are } \\
\text { computational-intensive. } \\
\text { Previous methods cannot } \\
\text { provide full probability } \\
\text { density functions. In order to } \\
\text { forecast by minutes, the } \\
\text { Gaussian distribution cannot } \\
\text { represent the error } \\
\text { distributions }\end{array}$ & $\begin{array}{l}\text { With SBL, there is no need } \\
\text { to estimate some parameters } \\
\text { and thus there is less } \\
\text { computation time. The } \\
\text { model has better } \\
\text { performance than others }\end{array}$ & $\begin{array}{l}\text { The method performs } \\
\text { poorly with large } \\
\text { datasets. The accuracy } \\
\text { of the model is not the } \\
\text { best for very short- } \\
\text { term or very long-term } \\
\text { wind power forecasts }\end{array}$ \\
\hline $\begin{array}{l}\text { Sinha and } \\
\text { Steel }\end{array}$ & 2015 & $\begin{array}{l}\text { Failure prediction } \\
\text { and maintenance } \\
\text { planning and } \\
\text { execution }\end{array}$ & $\begin{array}{l}\text { Online CM data, } \\
\text { inspection reports, } \\
\text { service records, } \\
\text { component manuals, } \\
\text { wind r farm } \\
\text { information, etc. }\end{array}$ & $\begin{array}{l}\text { Key performance } \\
\text { indicators of } \\
\text { maintenance } \\
\text { regimes in operation }\end{array}$ & $\begin{array}{l}\text { A failure dependency } \\
\text { model is developed based } \\
\text { on BN taking into account } \\
\text { relationships between } \\
\text { failures and failure root } \\
\text { causes }\end{array}$ & $\begin{array}{l}\text { Failure prediction is difficult } \\
\text { because of inadequate } \\
\text { understanding of WT } \\
\text { behaviour under stochastic } \\
\text { conditions. There is a need for } \\
\text { a dedicated software tool and } \\
\text { relational database for O\&M } \\
\text { planning }\end{array}$ & $\begin{array}{l}\text { The failure dependency } \\
\text { database design is useful for } \\
\text { O\&M planning when } \\
\text { different failures, root } \\
\text { causes and their likelihoods } \\
\text { of occurrence are } \\
\text { interconnected }\end{array}$ & $\begin{array}{l}\text { More failure data is } \\
\text { required to improve } \\
\text { the reliability of the } \\
\text { model }\end{array}$ \\
\hline $\begin{array}{l}\text { de Bessa et } \\
\text { al. }\end{array}$ & 2016 & $\begin{array}{l}\text { Use of time-series } \\
\text { and data analysis to } \\
\text { detect and isolate } \\
\text { faults in a WT } \\
\text { system }\end{array}$ & $\begin{array}{l}\text { Wind speed, sensor } \\
\text { signal database, } \\
\text { probability of fault } \\
\text { occurrence from } \\
\text { Gibbs sampling }\end{array}$ & $\begin{array}{l}\text { Probability } \\
\text { indication of each } \\
\text { detected and } \\
\text { isolated fault }\end{array}$ & $\begin{array}{l}\text { A two-part fault detection } \\
\text { and isolation (FDI) system } \\
\text { was used. The fuzzy } \\
\text { Bayesian module is used } \\
\text { for classifying the detected } \\
\text { faults }\end{array}$ & $\begin{array}{l}\text { Using existing data and } \\
\text { model-based methods, not all } \\
\text { faults within a WT system can } \\
\text { be identified and isolated }\end{array}$ & $\begin{array}{l}\text { Fuzz Bayesian method was } \\
\text { able to detect and isolate } \\
\text { multiple faults occurring at } \\
\text { the same time by extracting } \\
\text { information through Gibbs } \\
\text { sampling }\end{array}$ & $\begin{array}{l}\text { In some instances, the } \\
\text { fuzzy-Bayesian model } \\
\text { confused a wind } \\
\text { variation with a fault }\end{array}$ \\
\hline Herp et al. & 2016 & $\begin{array}{l}\text { Continuous } \\
\text { monitoring and } \\
\text { performance } \\
\text { evaluation of WTs }\end{array}$ & SCADA data & $\begin{array}{l}\text { Prediction of } \\
\text { bearing failure (by } \\
\text { over-temperature) }\end{array}$ & $\begin{array}{l}\text { Continuous monitoring as } \\
\text { a maintenance strategy } \\
\text { was used }\end{array}$ & $\begin{array}{l}\text { Threshold detection has been } \\
\text { used in the past for WT } \\
\text { monitoring. It does not take } \\
\text { into consideration the } \\
\text { probabilistic events within the }\end{array}$ & $\begin{array}{l}\text { The BN method takes into } \\
\text { account the likelihood of the } \\
\text { classification, making } \\
\text { supervised controls more } \\
\text { flexible }\end{array}$ & $\begin{array}{l}\text { Misclassification rates } \\
\text { are still high with } \\
\text { Bayesian methods, } \\
\text { even though reduced }\end{array}$ \\
\hline
\end{tabular}




\begin{tabular}{|c|c|c|c|c|c|c|c|c|}
\hline & & $\begin{array}{l}\text { using multivariate } \\
\text { statistical model }\end{array}$ & & & & $\begin{array}{l}\text { system. BN was used because } \\
\text { the Hotelling's } \mathrm{T}^{2} \text { approach } \\
\text { did not consider the likelihood } \\
\text { of the classification }\end{array}$ & & \\
\hline $\begin{array}{l}\text { Park and } \\
\text { Law }\end{array}$ & 2016 & $\begin{array}{l}\text { Solving the wind } \\
\text { farm control } \\
\text { problem ry by } \\
\text { maximising wind } \\
\text { power output using } \\
\text { the BA algorithm }\end{array}$ & $\begin{array}{l}\text { Wind speed, wind } \\
\text { direction, number of } \\
\text { turbines, yaw set } \\
\text { angles, induction } \\
\text { factors }\end{array}$ & $\begin{array}{l}\text { Wind farm power } \\
\text { production }\end{array}$ & $\begin{array}{l}\text { The BA method is made of } \\
\text { two parts: learning and } \\
\text { optimisation. The non- } \\
\text { cooperative control } \\
\text { solutions are used as the } \\
\text { prior data for the BA } \\
\text { algorithm. Simulation was } \\
\text { performed for validation }\end{array}$ & $\begin{array}{l}\text { Conventional wind farm } \\
\text { control strategies are non- } \\
\text { cooperative in which the wake } \\
\text { effects cannot be accounted } \\
\text { for to maximise a collective } \\
\text { power output. The proposed } \\
\text { method in this study is based } \\
\text { on cooperative WF control }\end{array}$ & $\begin{array}{l}\text { The BA algorithm can find } \\
\text { improved output values for } \\
\text { every input. This method } \\
\text { requires limited amounts of } \\
\text { data for optimum control } \\
\text { estimations. Noisy function } \\
\text { values can also be used. }\end{array}$ & $\begin{array}{l}\text { Although BA } \\
\text { algorithms can use } \\
\text { noisy function values, } \\
\text { increased noise levels } \\
\text { in data reduces the rate } \\
\text { of convergence, } \\
\text { slowing down the } \\
\text { iteration process }\end{array}$ \\
\hline $\begin{array}{l}\text { Pattison et } \\
\text { al. }\end{array}$ & 2016 & $\begin{array}{l}\text { WT reliability } \\
\text { estimation taking } \\
\text { into account } \\
\text { environment factors, } \\
\text { accessibility, failure } \\
\text { modes, etc. }\end{array}$ & $\begin{array}{l}\text { SCADA data, CM } \\
\text { indications }\end{array}$ & $\begin{array}{l}\text { Probability of } \\
\text { failure of WT } \\
\text { gearbox, impact of } \\
\text { maintenance } \\
\text { actions, short-term } \\
\text { degradation forecast }\end{array}$ & $\begin{array}{l}\text { DBM method was used for } \\
\text { risk assessment and } \\
\text { maintenance scheduling of } \\
\text { WT gearboxes }\end{array}$ & $\begin{array}{l}\text { Conventional techniques do } \\
\text { not account for WT dynamic } \\
\text { behaviours }\end{array}$ & $\begin{array}{l}\text { Bayesian methods can help } \\
\text { capture the dynamic } \\
\text { degradation over time. } \\
\text { System state can be } \\
\text { estimated based on different } \\
\text { maintenance scenarios }\end{array}$ & N.A. \\
\hline $\begin{array}{l}\text { Ciobanu et } \\
\text { al. }\end{array}$ & 2017 & 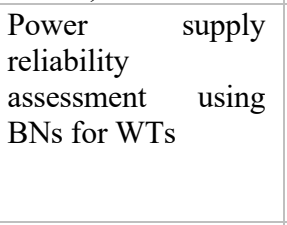 & $\begin{array}{l}\text { Minute-by-minute } \\
\text { meteorology } \\
\text { parameters such as } \\
\text { wind speed and solar } \\
\text { radiation }\end{array}$ & $\begin{array}{l}\text { Reliability } \\
\text { estimation }\end{array}$ & $\begin{array}{l}\text { Hugin software was used } \\
\text { to process the data. The } \\
\text { variables used were } \\
\text { discretised }\end{array}$ & $\begin{array}{l}\text { BNs are very complex and } \\
\text { difficult to synthetically } \\
\text { explain and the number of } \\
\text { possible structures is } \\
\text { exponential }\end{array}$ & $\begin{array}{l}\text { It is a useful tool for } \\
\text { monitoring and state } \\
\text { diagnosis of the wind power } \\
\text { supply network. It has the } \\
\text { capacity to predict future } \\
\text { availability conditions }\end{array}$ & $\begin{array}{l}\text { More variables need to } \\
\text { be included in the } \\
\text { probabilistic } \\
\text { estimation to ensure } \\
\text { robustness }\end{array}$ \\
\hline $\begin{array}{l}\text { Florian and } \\
\text { Sørensen }\end{array}$ & 2017 & $\begin{array}{l}\text { Impact of using risk- } \\
\text { based maintenance } \\
\text { on optimal O\&M } \\
\text { planning of WT } \\
\text { blades }\end{array}$ & $\begin{array}{l}\text { Initial crack size, } \\
\text { material parameters, } \\
\text { mean turbulence } \\
\text { intensity }\end{array}$ & $\begin{array}{l}\text { Posterior } \\
\text { distributions for } \\
\text { mean initial crack } \\
\text { size, material } \\
\text { parameters, total } \\
\text { risk/cost during } \\
\text { blade lifetime }\end{array}$ & $\begin{array}{l}\text { Reliability estimates for } \\
\text { blade degradation were } \\
\text { updated using BNs. Load } \\
\text { distribution was obtained } \\
\text { by Rainflow counting and } \\
\text { fitted to Weibull } \\
\text { distribution. Failure time } \\
\text { was estimated by MCS }\end{array}$ & $\begin{array}{l}\text { Current maintenance } \\
\text { strategies cause higher WT } \\
\text { downtimes and increase the } \\
\text { LCOE }\end{array}$ & $\begin{array}{l}\text { The degradation model can } \\
\text { be updated with inspection } \\
\text { results }\end{array}$ & $\begin{array}{l}\text { The method has not } \\
\text { taken into account } \\
\text { weather prediction for } \\
\text { O\&M schedules }\end{array}$ \\
\hline $\begin{array}{l}\text { Galanis, } \\
\text { G.et al. }\end{array}$ & 2017 & $\begin{array}{l}\text { Improved numerical } \\
\text { wind simulations to } \\
\text { reduce systematic } \\
\text { biases, error and } \\
\text { forecast uncertainty }\end{array}$ & $\begin{array}{l}\text { 4-year } \\
\text { meteorological } \\
\text { station data from } 9 \\
\text { stations }\end{array}$ & $\begin{array}{l}\text { Time series and } \\
\text { percentiles for real } \\
\text { and ideal data for } \\
\text { different } \\
\text { meteorological } \\
\text { stations }\end{array}$ & $\begin{array}{l}\text { Tests were performed for } \\
\text { both actual and ideal } \\
\text { datasets (to test data in a } \\
\text { controlled space). Weibull } \\
\text { prior distributions were } \\
\text { used for the Bayesian- } \\
\text { Kalman filter model }\end{array}$ & $\begin{array}{l}\text { Current solutions to wind } \\
\text { speed modelling } \\
\text { limitations with errors when } \\
\text { performing forecasts }\end{array}$ & $\begin{array}{l}\text { Reduced CPU memory, } \\
\text { elimination of systematic } \\
\text { prediction errors, reduction } \\
\text { of mean bias and real } \\
\text { convergence of the modelled } \\
\text { probability density function } \\
\text { to the observations }\end{array}$ & $\begin{array}{l}\text { Severe changes in data } \\
\text { used leads to } \\
\text { unexpected } \\
\text { discontinuities. } \\
\text { Difficulty in matching } \\
\text { the modelled and } \\
\text { observed data easily }\end{array}$ \\
\hline Jin and Liu & 2017 & $\begin{array}{l}\text { Reliability } \\
\text { improvement of WT } \\
\text { gearbox }\end{array}$ & $\begin{array}{l}\text { Historical gearbox } \\
\text { data and expert } \\
\text { opinion }\end{array}$ & $\begin{array}{l}\text { Failure probability } \\
\text { of each element of } \\
\text { the faulty gearbox }\end{array}$ & $\begin{array}{l}\text { Two gearbox failures were } \\
\text { considered: tooth surface } \\
\text { contact fatigue pitting and }\end{array}$ & $\begin{array}{l}\text { Minimum cut sets need to be } \\
\text { solved when using fault trees } \\
\text { as the method for reliability } \\
\text { calculations }\end{array}$ & $\begin{array}{l}\text { BNs are more suitable than } \\
\text { fault trees for reliability } \\
\text { analysis as they do not need } \\
\text { to solve minimum cut sets }\end{array}$ & N/A \\
\hline
\end{tabular}




\begin{tabular}{|c|c|c|c|c|c|c|c|c|}
\hline & & & & & $\begin{array}{l}\text { toot root bending fatigue } \\
\text { fracture }\end{array}$ & & $\begin{array}{l}\text { for reliability estimations, } \\
\text { avoiding the non-cross- } \\
\text { computing process }\end{array}$ & \\
\hline Jing et al. & 2017 & $\begin{array}{lr}\text { Fault diagnosis } \\
\text { improvement } & \text { to } \\
\text { improve wind } \\
\text { energy output }\end{array}$ & Fault data records & $\begin{array}{l}\text { Conditional } \\
\text { probability of } \\
\text { candidate faults and } \\
\text { their diagnosis }\end{array}$ & $\begin{array}{l}\text { First, a sensor data layer is } \\
\text { established and then a } \\
\text { fault list is used to create } \\
\text { the BN. The method was } \\
\text { tested using WF fault data }\end{array}$ & $\begin{array}{l}\text { Current approaches focus on } \\
\text { data from different } \\
\text { components and are difficult } \\
\text { to apply to the entire WT. It is } \\
\text { challenging to obtain } \\
\text { quantitative diagnostic results }\end{array}$ & $\begin{array}{l}\text { Faster fault } \\
\text { Improved fault diagnosis } \\
\text { accuracy }\end{array}$ & $\begin{array}{l}\text { Limited training data } \\
\text { and restricted } \\
\text { conditions make } \\
\text { diagnosis difficult }\end{array}$ \\
\hline Nabdi et al. & 2017 & $\begin{array}{l}\text { Decision logic to } \\
\text { choose preliminary } \\
\text { WT concepts using } \\
\text { probabilistic states } \\
\text { estimation }\end{array}$ & $\begin{array}{l}\text { Variables of state of } \\
\text { different } \\
\text { components, failure } \\
\text { rate of components, } \\
\text { unavailability of } \\
\text { components, repair } \\
\text { rate of components }\end{array}$ & $\begin{array}{l}\text { Probability of } \\
\text { failure of system } \\
\text { components for two } \\
\text { design concepts }\end{array}$ & N.A. & $\begin{array}{l}\text { Current modelling tools rely } \\
\text { primarily on expert } \\
\text { judgement, surveys and } \\
\text { manufacturing databases to } \\
\text { build WT structural models }\end{array}$ & $\begin{array}{l}\text { BN can be used to } \\
\text { incorporate numerous } \\
\text { design knowledge into a } \\
\text { model. BN has powerful } \\
\text { analytical and modelling } \\
\text { capacity. BN allows for } \\
\text { system state to be } \\
\text { determined for different } \\
\text { operational scenarios }\end{array}$ & $\begin{array}{l}\text { The model presented } \\
\text { did not fully account } \\
\text { for more criteria for } \\
\text { optimisation } \\
\text { improvement. }\end{array}$ \\
\hline $\begin{array}{l}\text { Nielsen and } \\
\text { Sørensen }\end{array}$ & 2017 & $\begin{array}{lr}\text { Optimal } & \text { O\&M } \\
\text { planning } & \text { with } \\
\text { lifetime } & \text { cost } \\
\text { estimation } & \text { using } \\
\text { CBM } & \end{array}$ & $\begin{array}{l}\text { Mean wind speed, } \\
\text { wave height }\end{array}$ & $\begin{array}{l}\text { Cost of inspections, } \\
\text { repairs and lost } \\
\text { production over WT } \\
\text { lifetime, power } \\
\text { production for 1- } \\
\text { hour intervals }\end{array}$ & $\begin{array}{l}\text { Bayesian updating is used } \\
\text { to determine posterior } \\
\text { probability for the } \\
\text { component state. Costs are } \\
\text { due to inspection, repair } \\
\text { and lost production in the } \\
\text { event of a failure }\end{array}$ & $\begin{array}{l}\text { The conventional methods do } \\
\text { not include inspection and } \\
\text { monitoring information in } \\
\text { decision making. Theoretical } \\
\text { tools become difficult to } \\
\text { handle because of increased } \\
\text { decision parameters }\end{array}$ & $\begin{array}{l}\text { Online monitoring can be } \\
\text { included into the model }\end{array}$ & N.A. \\
\hline $\begin{array}{l}\text { Pobočíková } \\
\text { et al }\end{array}$ & 2017 & $\begin{array}{l}\text { Wind } r \text { speed } \\
\text { modelling using } \\
\text { four probability } \\
\text { distributions }\end{array}$ & Wind speed & $\begin{array}{l}\text { Parameter } \\
\text { estimation using ML } \\
\text { method, histogram } \\
\text { of PDF for wind } \\
\text { speed }\end{array}$ & $\begin{array}{l}\text { Parameters were estimated } \\
\text { with STATISTICA and } \\
\text { wind speed was modelled } \\
\text { in MATLAB }\end{array}$ & N/A & N/A & N/A \\
\hline Tatsis et al. & 2017 & $\begin{array}{l}\text { Fatigue damage } \\
\text { estimation (response } \\
\text { prediction) of a WT }\end{array}$ & $\begin{array}{l}\text { Vibration data, } \\
\text { mean wind speed }\end{array}$ & $\begin{array}{l}\text { Estimated and actual } \\
\text { fatigue damage }\end{array}$ & $\begin{array}{l}\text { Modelled in FAST } \\
\text { software to generate the } \\
\text { vibrational data. Bayesian } \\
\text { filter was used for noisy } \\
\text { data }\end{array}$ & $\begin{array}{l}\text { The conventional stress } \\
\text { predictions do not account for } \\
\text { uncertain behaviour and } \\
\text { response of structures }\end{array}$ & $\begin{array}{lr}\text { Improved } & \text { accuracy of } \\
\text { dynamic } & \text { response } \\
\text { estimation using } \mathrm{CM} \text { data }\end{array}$ & $\begin{array}{l}\text { Using model-based } \\
\text { techniques for global } \\
\text { response analysis is } \\
\text { computationally } \\
\text { intensive }\end{array}$ \\
\hline Wang et al. & 2017 & $\begin{array}{l}\text { Wind power } \\
\text { forecasting using } \\
\text { both deterministic } \\
\text { and probabilistic } \\
\text { techniques }\end{array}$ & Wind power dataset & $\begin{array}{lr}\text { Wind } & \text { power } \\
\text { forecasts } & \text { using } \\
\text { Variation } & \text { Bayesian } \\
\text { method } & \end{array}$ & $\begin{array}{l}\text { A new model (ARMKR) } \\
\text { is used to process multi- } \\
\text { resolution wind power } \\
\text { data. A Gaussian mixture } \\
\text { model was used to model } \\
\text { the error }\end{array}$ & $\begin{array}{l}\text { Conventional methods like } \\
\text { quantile regression have } \\
\text { discontinuities in the PDF for } \\
\text { the wind power forecasts. } \\
\text { They ignore some information } \\
\text { when dealing with high- } \\
\text { resolution data }\end{array}$ & $\begin{array}{l}\text { Bayesian methods produce } \\
\text { continuous PDFs even for } \\
\text { interval forecasts. The } \\
\text { variational Bayesian method } \\
\text { is used to optimise all } \\
\text { parameters }\end{array}$ & N.A. \\
\hline
\end{tabular}




\begin{tabular}{|c|c|c|c|c|c|c|c|c|}
\hline Yang et al. & 2017 & $\begin{array}{l}\text { Prediction of wind } \\
\text { power using Naïve } \\
\text { Bayesian with } \\
\text { particler swarm } \\
\text { optimisation } \\
\text { and rough set (RS) }\end{array}$ & $\begin{array}{l}\text { Numerical wind } \\
\text { power }(\mathrm{NWP}) \text {, wind } \\
\text { speed }\end{array}$ & $\begin{array}{l}\text { Prediction intervals } \\
\text { at different } \\
\text { confidence levels, } \\
\text { segmentation and } \\
\text { non-segmentation } \\
\text { optimisation } \\
\text { prediction intervals }\end{array}$ & $\begin{array}{l}\text { Data (numerical wind } \\
\text { power and wind speed) } \\
\text { were recorded every } 15 \\
\text { minutes. RS theory was } \\
\text { used to handle the datasets } \\
\text { and Naïve Bayesian } \\
\text { classifier was used to } \\
\text { establish a power class }\end{array}$ & $\begin{array}{l}\text { The accuracy of conventional } \\
\text { methods depends largely on } \\
\text { the point forecasting value. } \\
\text { Previous methods also require } \\
\text { large computational capacity } \\
\text { and can be limited for real } \\
\text { applications }\end{array}$ & $\begin{array}{l}\text { Higher } \\
\text { performance, prediction } \\
\text { coverage and nigher } \\
\text { average bandwidth for wind } \\
\text { power forecasting intervals }\end{array}$ & N.A. \\
\hline $\begin{array}{l}\text { Afshari- } \\
\text { Igder et al. }\end{array}$ & 2018 & $\begin{array}{l}\text { Probabilistic wind } \\
\text { forecasting }\end{array}$ & $\begin{array}{l}\text { Historical wind } \\
\text { power data }\end{array}$ & $\begin{array}{l}\text { Optimal prediction } \\
\text { intervals } \\
\text { different times }\end{array}$ & $\begin{array}{l}\text { Approximation methods } \\
\text { for prediction } \\
\text { uncertainties } \\
\text { Bayesian methods are } \\
\text { used to obtain the PI }\end{array}$ & $\begin{array}{l}\text { Uncertainty in wind power } \\
\text { forecasting cannot be solved } \\
\text { by conventional methods }\end{array}$ & $\begin{array}{l}\text { More reliable PIs of wind } \\
\text { power improve forecasting } \\
\text { accuracy }\end{array}$ & N.A. \\
\hline $\begin{array}{l}\text { Asgarpour } \\
\text { and } \\
\text { Sørensen }\end{array}$ & $2018 \mathrm{a}$ & $\begin{array}{l}\text { Prediction of } \\
\text { maintenance time } \\
\text { using a Bayesian- } \\
\text { based prognostic } \\
\text { model }\end{array}$ & $\begin{array}{l}\text { Average failure rate, } \\
\text { operational data } \\
\text { like: degradation } \\
\text { data and RUL of the } \\
\text { components, expert } \\
\text { judgements }\end{array}$ & $\begin{array}{l}\text { Posterior } \\
\text { degradation model } \\
\text { of a component } \\
\text { based on updated } \\
\text { shape and scale } \\
\text { parameters }\end{array}$ & $\begin{array}{l}\text { Posterior degradation } \\
\text { model is updated based on } \\
\text { updated shape and scale } \\
\text { parameters from CM- } \\
\text { based observations }\end{array}$ & $\begin{array}{l}\text { Computational complexity } \\
\text { limits the use of many } \\
\text { prognostic approaches in } \\
\text { practice }\end{array}$ & $\begin{array}{l}\text { BN allows more than one } \\
\text { threshold and predictive } \\
\text { maintenance strategy to be } \\
\text { considered. It is applicable } \\
\text { to different components and } \\
\text { failure modes }\end{array}$ & N.A. \\
\hline $\begin{array}{l}\text { Asgarpour } \\
\text { and } \\
\text { Sørensen }\end{array}$ & $2018 b$ & $\begin{array}{l}\text { Fault detection for a } \\
\text { WT component } \\
\text { using a hybrid multi- } \\
\text { agent model }\end{array}$ & $\begin{array}{l}\text { Diagnostic model } \\
\text { input/agents, } \\
\text { SCADA data } \\
\text { (vibration, } \\
\text { temperature and oil } \\
\text { particle), prognostic } \\
\text { model input }\end{array}$ & $\begin{array}{l}\text { Posterior confidence } \\
\text { levels of diagnostic } \\
\text { agents for main } \\
\text { bearing, short term } \\
\text { O\&M planning } \\
\text { framework }\end{array}$ & $\begin{array}{l}\text { Both confidence matrix } \\
\text { and diagnosis matrix were } \\
\text { inputted in the decision } \\
\text { model. Faults detected by } \\
\text { the diagnosis agents are } \\
\text { confirmed by inspections, } \\
\text { and the initial confidence } \\
\text { matrix is updated by BN }\end{array}$ & $\begin{array}{l}\text { There is no generic diagnostic } \\
\text { model suitable for all WTs. } \\
\text { Conventional methods result } \\
\text { in high O\&M costs due to } \\
\text { unplanned failures of WT } \\
\text { components }\end{array}$ & $\begin{array}{l}\text { Improved fault detection by } \\
\text { Bayesian updating of the } \\
\text { initial confidence matrix. It } \\
\text { can help in short-term O\&M } \\
\text { planning with significant } \\
\text { cost reduction }\end{array}$ & N.A. \\
\hline Ding et al. & 2018 & $\begin{array}{lr}\text { Fatigue } & \text { life } \\
\text { prediction of } \mathrm{WT} \\
\text { gearbox } \\
\text { varying-load } \\
\text { method }\end{array}$ & $\begin{array}{l}\text { Material } \\
\text { teeth roperties, } \\
\text { Young's mumber, } \\
\text { Poisson's ratus, } \\
\text { diametral pitch, base } \\
\text { circle radius, outer } \\
\text { circle, pressure } \\
\text { angle }\end{array}$ & $\begin{array}{lr}\text { Fatigue life } & \text { is } \\
\text { predicted } & \text { and } \\
\text { updated with } & \text { wayesian methods }\end{array}$ & $\begin{array}{l}\mathrm{CM} \text { data and uncertain } \\
\text { parameter distributions are } \\
\text { used to model the } \\
\text { degradation process. } \\
\text { Crack is propagated based } \\
\text { on stress analysis in } \\
\text { FRANC2D programme }\end{array}$ & $\begin{array}{l}\text { Existing methods use constant } \\
\text { loads to approximate external } \\
\text { load during fatigue prognosis. } \\
\text { When using model-based } \\
\text { methods, it is difficult to } \\
\text { model complex components }\end{array}$ & $\begin{array}{l}\text { Uncertainty is reduced and } \\
\text { life prediction is improved } \\
\text { by Bayesian updating given } \\
\text { the measured crack length }\end{array}$ & N.A. \\
\hline Han et al. & 2018 & $\begin{array}{l}\text { Probabilistic wind } \\
\text { speed forecasting } \\
\text { with comparing } \\
\text { post-processing } \\
\text { methods }\end{array}$ & Wind speed data & $\begin{array}{l}\text { Verification rank } \\
\text { histogram of EMOS } \\
\text { and BMA forecasts }\end{array}$ & $\begin{array}{l}\text { Six } \\
\text { methods are used for } \\
\text { ensemble model output } \\
\text { statistics (EMOS) and } \\
\text { Bayesian model averaging } \\
\text { (BMA) models }\end{array}$ & $\begin{array}{l}\text { Current forecasting methods } \\
\text { are subject to bias }\end{array}$ & $\begin{array}{l}\text { Among the forecasting } \\
\text { methods, the BMA models } \\
\text { had the highest accuracy }\end{array}$ & $\begin{array}{lr}\text { Different } & \text { prediction } \\
\text { accuracies } & \text { for } \\
\text { different stations were } \\
\text { observed }\end{array}$ \\
\hline
\end{tabular}




\begin{tabular}{|c|c|c|c|c|c|c|c|c|}
\hline Herp et al. & 2018 & $\begin{array}{l}\text { Bearing failure } \\
\text { prediction using } \\
\text { Bayesian methods }\end{array}$ & $\begin{array}{l}\text { Temperature } \\
\text { measurement } \\
\text { residuals }\end{array}$ & $\begin{array}{lr}\text { Failure } & \text { state } \\
\text { prediction, } & \text { RUL } \\
\text { prediction } & \text { given } \\
\text { run-to-failure } & \text { time } \\
\text { series } & \end{array}$ & $\begin{array}{l}\text { Run-to-failure time of } \\
\text { bearings is used to train } \\
\text { the prior data used in the } \\
\text { model. Hyperparameter } \\
\text { are updated to train the } \\
\text { model }\end{array}$ & $\begin{array}{l}\text { Other methods of fault } \\
\text { estimation do not consider } \\
\text { improvement of the model } \\
\text { precision }\end{array}$ & $\begin{array}{l}\text { It predicts the bearing over- } \\
\text { temperature events. The } \\
\text { accuracy improves on a } \\
\text { daily timescale while } \\
\text { precision improves on a } \\
\text { weekly timescale }\end{array}$ & $\begin{array}{l}\text { Convergence is only } \\
\text { possible with a large } \\
\text { number of time series } \\
\text { because of the strong- } \\
\text { data-driven nature of } \\
\text { the model }\end{array}$ \\
\hline $\begin{array}{l}\text { Joshuva and } \\
\text { Sugumaran }\end{array}$ & 2018 & $\begin{array}{l}\text { Fault identification } \\
\text { in WTs }\end{array}$ & $\begin{array}{lr}\text { Vibration } & \text { data } \\
\text { obtained } & \text { from } \\
\text { accelerometer } & \end{array}$ & $\begin{array}{l}\text { Classification } \\
\text { results and accuracy } \\
\text { of different } \\
\text { classifiers }\end{array}$ & $\begin{array}{l}\text { Five blade failure features } \\
\text { were identified using ML } \\
\text { and statistical analysis. Six } \\
\text { classifiers, including Lazy } \\
\text { Bayesian Rules Classifier } \\
\text { (LBRC), were applied }\end{array}$ & $\begin{array}{l}\text { Conventional methods require } \\
\text { performance improvements } \\
\text { for considering different types } \\
\text { of fault parameters }\end{array}$ & $\begin{array}{l}\text { LBRC model requires little } \\
\text { running time }\end{array}$ & $\begin{array}{l}\text { LBRC classifier was } \\
\text { seen not to be superior } \\
\text { to other classifiers. It } \\
\text { may require more } \\
\text { memory than non-lazy } \\
\text { algorithms }\end{array}$ \\
\hline $\begin{array}{l}\text { Reder and } \\
\text { Melero }\end{array}$ & 2018 & $\begin{array}{l}\text { Predictive failure } \\
\text { modelling for } \\
\text { improved O\&M of } \\
\text { WTs }\end{array}$ & $\begin{array}{l}\text { Failure data for } \\
\text { components, } \\
\text { environmental data } \\
\text { (wind speed, rain, } \\
\text { temperature), WT } \\
\text { data (hub height, } \\
\text { diameter, etc.) }\end{array}$ & $\begin{array}{l}\text { Monthly predicted } \\
\text { failures, conditional } \\
\text { probabilities of } \\
\text { failure for different } \\
\text { components }\end{array}$ & $\begin{array}{l}\text { Naïve Bayesian classifier } \\
\text { was used to incorporate } \\
\text { uncertainty. Sensitivity of } \\
\text { failures in WT subsystems } \\
\text { was analysed based on } \\
\text { accuracy and Matthews } \\
\text { correlation coefficient }\end{array}$ & $\begin{array}{l}\text { Conventional failure } \\
\text { prediction methods assume } \\
\text { constant failure rates. } \\
\text { Advanced WT reliability } \\
\text { models do not always account } \\
\text { for the variable environmental } \\
\text { conditions of the WTs }\end{array}$ & $\begin{array}{l}\text { Improved prediction } \\
\text { accuracy }\end{array}$ & $\begin{array}{l}\text { The technique for the } \\
\text { pitch and yaw system } \\
\text { had poor performance }\end{array}$ \\
\hline Song et al. & 2018 & $\begin{array}{l}\text { WT health state } \\
\text { monitoring using } \\
\text { Bayesian methods }\end{array}$ & $\begin{array}{l}\text { 10-minute SCADA } \\
\text { data }\end{array}$ & $\begin{array}{lr}\begin{array}{l}\text { Distributions } \\
\text { normal of } \\
\text { abnormal and }\end{array} \\
\text { SCADA parameters, } \\
\text { variations r of } \\
\text { SCADA parameter } \\
\text { values for WTs }\end{array}$ & $\begin{array}{l}\text { Three Bayesian methods } \\
\text { were used (bin, } \\
\text { multivariate normal- } \\
\text { based, and copula). Data } \\
\text { from two WTs were used } \\
\text { from 10-minute data for } 2 \\
\text { months }\end{array}$ & $\begin{array}{l}\text { Higher resolution diagnosis is } \\
\text { required for WT health state } \\
\text { monitoring }\end{array}$ & $\begin{array}{l}\text { Bayesian methods are } \\
\text { superior to power curve- } \\
\text { based monitoring method. } \\
\text { The Bayesian-copula } \\
\text { method was very effective in } \\
\text { one-step ahead prediction }\end{array}$ & $\begin{array}{l}\text { It is challenging to } \\
\text { determine the most } \\
\text { useful criteria for } \\
\text { identifying the normal } \\
\text { and abnormal } \\
\text { conditions using } \\
\text { SCADA data }\end{array}$ \\
\hline Uzunoğlu & 2018 & $\begin{array}{l}\text { Development of a } \\
\text { BN model for O\&M } \\
\text { planning using } \\
\text { subjective expert } \\
\text { opinions }\end{array}$ & $\begin{array}{l}\text { SCADA data, expert } \\
\text { opinions }\end{array}$ & $\begin{array}{l}\text { Posterior probability } \\
\text { density function } \\
\text { updates, fused } \\
\text { subjective opinions, } \\
\text { and cost assessment }\end{array}$ & $\begin{array}{l}\text { BN is updated with newly } \\
\text { available SCADA data. } \\
\text { The model is applied to } \\
\text { data of pitch control } \\
\text { failures from 2009-2015 }\end{array}$ & $\begin{array}{l}\text { Current methods do not } \\
\text { quantify uncertainties from } \\
\text { software reliability, control } \\
\text { system reliability, and weather } \\
\text { conditions }\end{array}$ & $\begin{array}{l}\text { The model is updated with } \\
\text { new information (SCADA } \\
\text { data and expert opinion). } \\
\text { Method can be extended to } \\
\text { different maintenance data }\end{array}$ & N.A. \\
\hline $\begin{array}{l}\text { Lazakis and } \\
\text { Kougioumtz } \\
\text { oglou }\end{array}$ & 2019 & $\begin{array}{l}\text { Risk and cost } \\
\text { analyses of different } \\
\text { lifecycle phases of } \\
\text { offshore WTs using } \\
\text { BNs for installation } \\
\text { and O\&M }\end{array}$ & $\begin{array}{l}\text { Failure data for each } \\
\text { WT subcomponent, } \\
\text { failure cause data } \\
\text { (from OREDA } \\
\text { Handbook) }\end{array}$ & $\begin{array}{l}\text { Failure probabilities } \\
\text { for different } \\
\text { components, } \\
\text { estimation of annual } \\
\text { cost of failure }\end{array}$ & $\begin{array}{l}\text { Main system was divided } \\
\text { into } 11 \text { subsystems. BN } \\
\text { was used to validate } \\
\text { FMECA and HAZID } \\
\text { results }\end{array}$ & $\begin{array}{l}\text { Identifying hazards accurately } \\
\text { is a key in decision-making }\end{array}$ & $\begin{array}{l}\text { BN is a more flexible } \\
\text { method than FTA/ETA, as it } \\
\text { can combine both objective } \\
\text { and subjective data. BN } \\
\text { improves reliability and } \\
\text { criticality analysis for } \\
\text { improved O\&M planning }\end{array}$ & N.A. \\
\hline $\begin{array}{l}\text { Moghaddass } \\
\text { and Sheng }\end{array}$ & 2019 & \begin{tabular}{l}
\multicolumn{3}{l}{ Cost-sensitive } \\
anomaly detection \\
using BN with \\
limited data
\end{tabular} & $\begin{array}{l}\text { Real-time sensor } \\
\text { data }\end{array}$ & 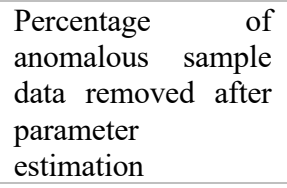 & $\begin{array}{l}2500 \text { sample data were } \\
\text { used ( } 2000 \text { for training } \\
\text { and } 500 \text { for modelling). } \\
\text { MCMC was used for data } \\
\text { training }\end{array}$ & $\begin{array}{l}\text { Conventional data-driven } \\
\text { anomaly detection methods } \\
\text { are inefficient. A trade-of } \\
\text { between misclassification }\end{array}$ & $\begin{array}{l}\text { The cost sensitive BN } \\
\text { decision tool allows for } \\
\text { anomaly prediction with } \\
\text { lower cost and risk. It can be }\end{array}$ & $\begin{array}{l}\text { Intensive } \\
\text { computations. During } \\
\text { data training, not all } \\
\text { anomalous samples } \\
\text { can be found }\end{array}$ \\
\hline
\end{tabular}




\begin{tabular}{|c|c|c|c|c|c|c|c|c|}
\hline & & & & & & $\begin{array}{l}\text { errors and detection rates must } \\
\text { be defined }\end{array}$ & $\begin{array}{l}\text { used with limited data for } \\
\text { training and modelling }\end{array}$ & \\
\hline Wang et al. & $2019 a$ & $\begin{array}{l}\text { Improved accuracy } \\
\text { in wind power } \\
\text { forecasts using } \\
\text { inconsistent datasets }\end{array}$ & $\begin{array}{ll}\text { Historical } & \text { wind } \\
\text { power data, } & \text { wind } \\
\text { speed data } & \end{array}$ & $\begin{array}{l}\text { It estimated power } \\
\text { curves to show } \\
\text { normal and } \\
\text { inconsistent datasets }\end{array}$ & $\begin{array}{l}\text { HSRM and RSRM are } \\
\text { optimised by BN methods. } \\
6000 \text { WT datasets are } \\
\text { collected at different } \\
\text { seasons of the year, } \\
\text { collected every } 10 \text { minutes }\end{array}$ & $\begin{array}{l}\text { There are inconsistencies in } \\
\text { available wind power data. } \\
\text { Parametric techniques are } \\
\text { limited in modelling the } \\
\text { dynamic characteristics of } \\
\text { power curves }\end{array}$ & $\begin{array}{l}\text { HSRM and RSRM are } \\
\text { considered good methods } \\
\text { for improving the quality of } \\
\text { wind power forecasts }\end{array}$ & $\begin{array}{l}\text { The methods require } \\
\text { more training times } \\
\text { for improved accuracy }\end{array}$ \\
\hline Wang et al. & $2019 b$ & $\begin{array}{l}\text { Use of sparse } \\
\text { Bayesian-based } \\
\text { method to improve } \\
\text { wind speed } \\
\text { forecasting }\end{array}$ & Wind speed data & $\begin{array}{l}\text { The performance of } \\
\text { different models } \\
\text { was compared using } \\
\text { the same datasets }\end{array}$ & $\begin{array}{l}\text { Sparse Bayesian-based } \\
\text { robust functional } \\
\text { regression model was } \\
\text { developed to forecast } 10- \\
\text { minute ahead wind speed }\end{array}$ & $\begin{array}{l}\text { There are usually outliers in } \\
\text { the dataset that affect accuracy } \\
\text { of predictions. Pre-processing } \\
\text { accuracy depends on the } \\
\text { quality of pre-processed data }\end{array}$ & $\begin{array}{l}\text { The downsides of having } \\
\text { outliers within the datasets } \\
\text { are reduced. The method is } \\
\text { also more robust because of } \\
\text { high-resolution data }\end{array}$ & N.A. \\
\hline Xie et al. & 2019 & $\begin{array}{l}\text { Improved short-term } \\
\text { probabilistic wind } \\
\text { power forecasting }\end{array}$ & $\begin{array}{ll}\text { Historical wind } \\
\text { power data, wind } \\
\text { ramp datasets }\end{array}$ & $\begin{array}{l}\text { Prediction error for } \\
\text { wind ramp datasets, } \\
\text { posterior predictive } \\
\text { wind power } \\
\text { distributions, } \\
\text { probabilistic wind } \\
\text { power forecasts }\end{array}$ & $\begin{array}{l}1000 \text { datasets of hourly } \\
\text { wind power were used. No } \\
\text { performance improvement } \\
\text { is observed when } \\
\text { historical data increases }\end{array}$ & $\begin{array}{l}\text { Conventional methods } \\
\text { underestimate uncertainty in } \\
\text { wind power forecasts. They do } \\
\text { not fully describe the } \\
\text { predicted wind power } \\
\text { distribution }\end{array}$ & $\begin{array}{l}\text { Reliable for informing } \\
\text { regarding real-time risk } \\
\text { management }\end{array}$ & N.A. \\
\hline Zhong et al. & 2019 & $\begin{array}{lr}\text { Real-time } & \text { fault } \\
\text { diagnosis } & \text { using } \\
\text { efficient } & \text { signal } \\
\text { processing methods }\end{array}$ & $\begin{array}{l}\text { Vibration signals } \\
\text { from online } \mathrm{CM} \\
\text { system of the } \\
\text { gearbox }\end{array}$ & $\begin{array}{l}\text { Identification of } \\
\text { faults more quickly } \\
\text { and precisely than } \\
\text { traditional } \\
\text { techniques }\end{array}$ & $\begin{array}{l}\text { Signal data pre-processing } \\
\text { and pattern recognition } \\
\text { with ML techniques. WT } \\
\text { gearbox fault features } \\
\text { were extracted using } \\
\text { Hilbert-Huang transforms } \\
\text { and correlation methods }\end{array}$ & $\begin{array}{l}\text { Conventional fault diagnosis } \\
\text { techniques lead to large costs } \\
\text { due to big and noisy datasets }\end{array}$ & $\begin{array}{l}\text { Since this method is data- } \\
\text { driven, it does not require } \\
\text { many parameters. This is a } \\
\text { more adaptive and accurate } \\
\text { fault diagnosis method }\end{array}$ & $\begin{array}{l}\text { The accuracy of } \\
\text { diagnosis depends on } \\
\text { quality of input data. It } \\
\text { is only designed for } \\
\text { binary classification } \\
\text { problems (i.e. healthy } \\
\text { or faulty) }\end{array}$ \\
\hline
\end{tabular}

